\section{Congenital disorders of glycosylation IIa cause growth retardation, mental retardation, and facial dysmorphism}

EDITOR-Congenital disorders of glycosylation (CDG) are a heterogeneous group of autosomal recessive multisystemic conditions causing severe central nervous system and multivisceral disorders resulting from impairment of the glycosylation pathway. ${ }^{1-3}$ Two disease causing mechanisms have been identified so far. CDG I is caused by a defect in the assembly of the dolicholpyrophosphate oligosaccharide precursor of $\mathrm{N}$-glycans and its transfer to the peptide chain, while CDG II results from a defect in the processing of N-glycans. ${ }^{3}$ CDG I and II have distinct patterns of abnormal glycosylation depending on the reduction of the glycan chain number or its structure. CDG I, the most frequent form, is the result of different enzyme deficiencies: phosphomannomutase (CDG Ia), phosphomannose isomerase (CDG Ib), and glucosyltransferase (CDG Ic)..$^{3-6}$ CDG IIa is characterised by a defect in $\mathrm{N}$-acetylglucosaminyltransferase II and only two cases have been reported previously. ${ }^{7-11}$ Here, we report a new case of CDG IIa sharing a number of clinical features with the two previously reported cases and emphasising the clinical differences from CDG I.

A boy was born at term to unrelated, healthy parents after a normal pregnancy and delivery, birth weight $3050 \mathrm{~g}$, length $48 \mathrm{~cm}$, and $\mathrm{OFC} 35 \mathrm{~cm}$. At 3 months of age, hypotonia, feeding difficulties, and diarrhoea were noted. A milk protein intolerance was suspected and he was put on a milk free formula until the age of 4 years. He was first referred to our genetic unit at 8 years of age because of mental retardation and facial dysmorphism. On examination, he had severe mental retardation with no speech and an unstable gait. Dysmorphic features included fine hair, large ears, a beaked nose with hypoplastic nasal alae, a long philtrum, thin vermilion border of the upper lip, everted lower lip, large teeth, and gum hypertrophy (fig 1). Long standing feeding difficulties and diarrhoea had resulted in severe growth retardation (height $109.9 \mathrm{~cm}$ (-3 SD), weight $20 \mathrm{~kg}(-2.5 \mathrm{SD})$, OFC $50.5 \mathrm{~cm}$ (-2 SD)). Chromosome analysis was normal and no diagnosis was made at that time. At 11 years of age, dysmorphic features, severe mental retardation, diarrhoea, and growth retardation were still present (height $120.8 \mathrm{~cm}$ (-4 SD), weight 23 $\mathrm{kg}(-2.5 \mathrm{SD})$, OFC $50.5 \mathrm{~cm}$ (-2 SD)). Kyphosis, widely spaced (but not inverted) nipples, and pectus excavatum were also noted. Echocardiography, MRI, and fundoscopy were normal but an electroretinogram was altered with a severe reduction of both cone and rod responses.

Routine laboratory investigations were performed and showed normal serum creatinine, cholesterol, and alkaline phosphatase concentrations but raised ASAT (195 U/1, normal $<20 \mathrm{U} / \mathrm{l})$. Coagulation studies were performed before a tooth extraction and showed decreased blood coagulation factors (factor IX 60\%, normal 65-160; factor XI 30\%, normal 60-160; factor XII 73\%, normal 50-160; protein C 30\%, normal 70-130; protein S $60 \%$, normal 70-130), abnormal prothrombin time (19 seconds, normal 25 seconds), and activated partial prothromboplastin time (46 seconds, normal $32 \pm 8$ seconds). The combination of mental retardation, failure to thrive, abnormal electroretinogram, and coagulation abnormalities were highly suggestive of CDG.

Western blot analysis of various serum glycoproteins (transferrin, $\alpha_{1}$-antitrypsin, haptoglobin) were performed as previously described ${ }^{1213}$ and showed an abnormal pattern with one single lower band (fig 2A). Similarly, isoelectric focusing of serum transferrin showed a markedly abnormal pattern corresponding to an increase of the disialotransferrin and a nearly complete absence of hexa-, penta-, and tetrasialotransferrins in the patient (fig 2B). These patterns were identical to those previously reported in CDG IIa. ${ }^{10}$ Activity of $\mathrm{N}$-acetylglucosaminyltransferase II (MGAT2) was determined at $37^{\circ} \mathrm{C}$ on cultured skin fibroblasts, according to Tan et $a l^{9}{ }^{9}$ and was profoundly deficient $(1.9 \pm 0.4 \mu \mathrm{mol} / \mathrm{g}$ protein $/ \mathrm{h}$, control $38.9 \pm 2.4$ $\mu \mathrm{mol} / \mathrm{g}$ protein $/ \mathrm{h})$.

Finally, direct sequencing of the coding region for the catalytic domain of the MGAT2 gene identified two distinct point mutations: a missense mutation changing an adenine into a guanine at nt $952(\mathrm{~N} 318 \mathrm{D})$ and a nonsense mutation at nucleotide 1017 (C339X) leading to a premature stop codon. The father was found to be heterozygous for the N318D mutation and the mother for the C339X mutation.

We report the third observation of CDG IIa in a child with chronic feeding difficulties of early onset, severe mental retardation, and dysmorphic facial features. The two patients reported previously had severe psychomotor retardation with no speech, stereotypic hand washing behaviour, and epilepsy (the last two features were not observed in our case) (table 1). Growth retardation was also consistently observed in all three cases, but major feeding difficulties with chronic diarrhoea were only observed in our case. Dysmorphic features were mentioned in all cases and appeared distinctive with a beaked nose, long philtrum, thin vermilion border of the upper lip, large ears, gum hypertrophy, and thoracic deformity. Ventricular
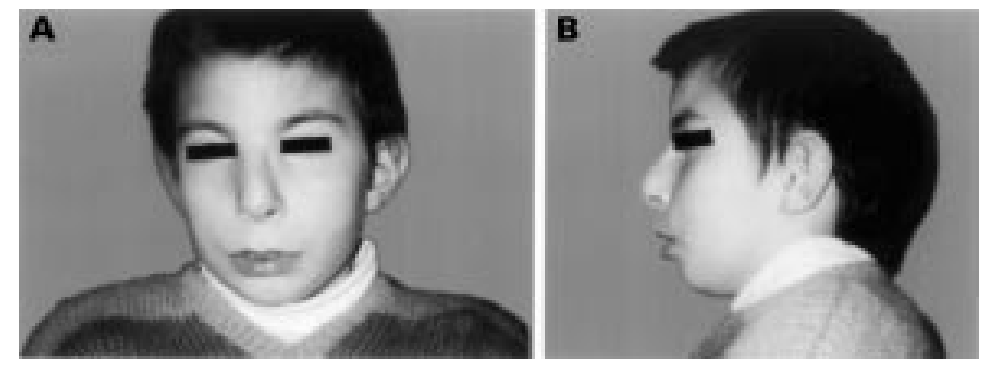

Figure 1 Patient at the age of 11 years. Note the beaked nose with hypoplastic nasal alae, long philtrum, thin vermilion border of the upper lip, everted lower lip, and short neck. 

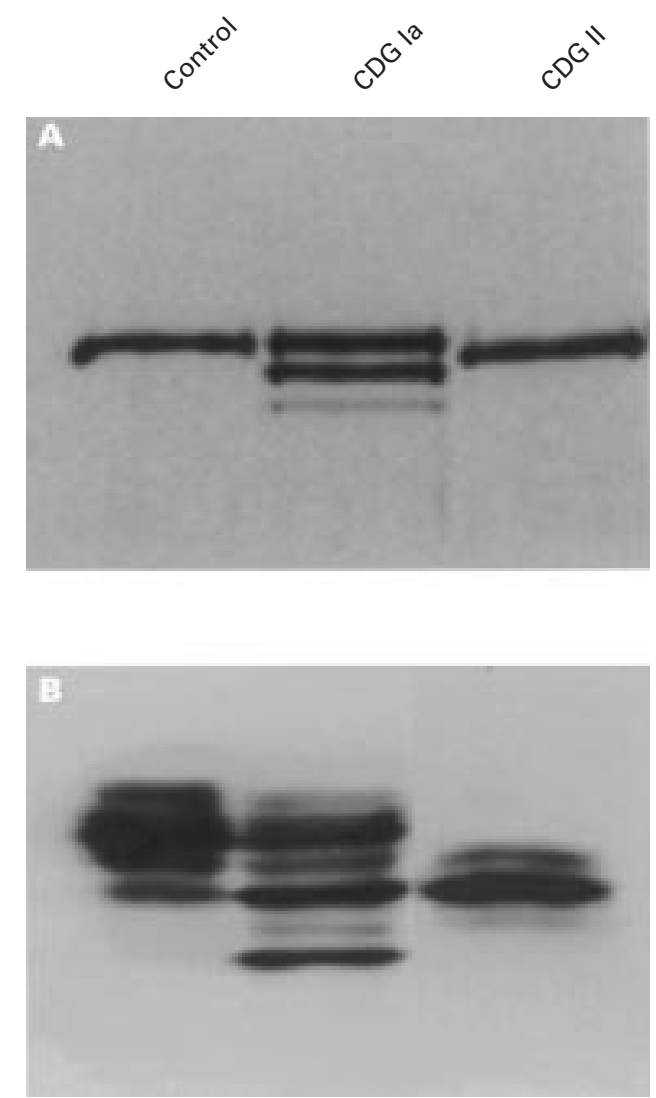

Figure 2 Pattern of serum transferrin on SDS/PAGE $(A)$ and isoelectric focusing (B) from a control, a CDG Ia reference patient, and the CDG IIa patient.

septal defect was observed in $2 / 3$ cases. In one case, MRI showed white matter lesions, ${ }^{11}$ but not in the two other cases. Finally, electroretinogram abnormalities affecting both cones and rods were observed in our case. Although CDG Ia and IIa are both multisystemic disorders with major nervous system involvement, they are also characterised by specific dysmorphic features. Inverted nipples, skin lipodystrophy, peripheral neuropathy, and cerebellar hypoplasia have never been observed in CDG IIa and the psychomotor retardation appears to be more severe.

All the CDG cases share common biological features, namely liver abnormalities and decreased coagulation factors. All cases result from an alteration of the $\mathrm{N}$-glycosylation pathway through distinct mechanisms. In CDG IIa, N-acetylglucosaminyltransferase II deficiency hampers transfer of the $\mathrm{N}$-acetylglucosaminyl residue, the first residue of the antennae, to its substrate. The lack of one glycoprotein antenna causes a molecular weight loss and a reduction in electrical charge. ${ }^{10}$ While the mutations identified in our patient are different from those previously reported, they all occur in the C-terminal end of the catalytic domain of the protein. This domain is highly conserved between rat and humans. ${ }^{9}$ MGAT2, which is present in the trans Golgi apparatus, appears to be an essential enzymatic step for the biosynthesis of complex Asn linked glycans. The observation of severe multisystemic developmental anomalies in CDG IIa patients is suggestive of a crucial role of complex $\mathrm{N}$-glycans in human development and particularly in the nervous system.

No treatment is available for CDG IIa at present. However, the identification of the enzyme defect and the disease causing gene make prenatal diagnosis feasible in this rare but underdiagnosed autosomal recessive disorder.

Although all types of CDG share common features, the clinical manifestations of CDG IIa differ from the typical features of CDG I. In two cases (including ours), the diagnosis was fortuitous (coagulation testing) and made only after the age of 8 years. We therefore suggest giving consideration to the diagnosis of CDG IIa when dealing with the association of developmental delay, dysmorphic features, and growth retardation.

Table 1 Clinical profile of our patient compared to the previously reported cases

\begin{tabular}{|c|c|c|c|}
\hline & faeken et al ${ }^{8}$ & Ramaekers et al ${ }^{11}$ & This case \\
\hline Ethnic origin & Belgian & $\begin{array}{l}\text { Iranian } \\
\text { Consanguineous parents }\end{array}$ & French \\
\hline Birth weight & $3250 \mathrm{~g}$ & ? & $3050 \mathrm{~g}$ \\
\hline Birth length & $50 \mathrm{~cm}$ & & $48 \mathrm{~cm}$ \\
\hline Head circumference & $35 \mathrm{~cm}$ & & $35 \mathrm{~cm}$ \\
\hline Presenting symptom & Hypotonia at birth & Developmental delay & $\begin{array}{l}\text { Feeding difficulties } \\
\text { Diarrhoea at } 3 \text { months }\end{array}$ \\
\hline Method of diagnosis & Investigation of the coagulation & $?$ & Investigation of the coagulation \\
\hline Age at diagnosis & $9.5 \mathrm{y}$ & $3 y$ & $11 \mathrm{y}$ \\
\hline \multicolumn{4}{|l|}{ Neurological symptoms } \\
\hline \multirow{2}{*}{ Developmental delay } & Severe & Severe & Severe \\
\hline & $\begin{array}{l}\text { A few steps without support } \\
\text { Monotonous sounds }\end{array}$ & Generalised hypotonia & $\begin{array}{l}\text { No speech at } 11 \\
\text { Unstable gait }\end{array}$ \\
\hline Epilepsy & Yes, at 6 & Yes & No \\
\hline Abnormal behaviour & Stereotypic & Hand washing movement & No \\
\hline Neuropathy & No & No & No \\
\hline Cerebellar hypoplasia & No & No & No \\
\hline \multirow[t]{3}{*}{ Failure to thrive } & + After $2 \mathrm{y}$ & + & + \\
\hline & L 3rd centile & L 3 rd-10th centile & $\mathrm{L}<-4 \mathrm{SD}$ \\
\hline & W 3rd centile & W 3rd-10th centile & $\mathrm{W}<-2.5 \mathrm{SD}$ \\
\hline Gastrointestinal problems & Volvulus of the stomach & - & Chronic diarrhoea \\
\hline Dysmorphic features & & Coarse face & \\
\hline Nose & Hooked & - & Beaked \\
\hline Lips & Thin & - & $\begin{array}{l}\text { Thin upper lip, } \\
\text { Everted lower lip }\end{array}$ \\
\hline Ears & Large, dysplastic & Large, low set & Large \\
\hline Gums & Hypertrophy & - & Hypertrophy \\
\hline Teeth & Large & - & Large \\
\hline Mandible & Prognathism & - & - \\
\hline Neck & Short & - & Short \\
\hline \multirow[t]{3}{*}{ Thorax } & - & - & Pectus excavatum \\
\hline & - & Widely spaced nipples & Widely spaced nipples \\
\hline & Kyphoscoliosis & - & Kyphosis \\
\hline Cardiac defect & Ventricular septal defect & Ventricular septal defect & - \\
\hline ERG & $?$ & $?$ & Altered \\
\hline Mutation & A1467G/A1467G & $\mathrm{C} 1551 \mathrm{~T} / \mathrm{C} 1551 \mathrm{~T}$ & A952G/T1017A \\
\hline
\end{tabular}


V CORMIER-DAIRE* $\mathrm{J} \mathrm{AMIEL}^{\star}$ $S$ VUILLAUMIER-BARROT $\dagger$ J TAN

G DURAND A MUNNICH* M LE MERRER* N SETATS

*Department of Genetics and INSERM U 393, Hoppital Necker Enfants Malades, 149 rue de Sèvres, 75743 Paris Cedex 15, France

†Department of Biochemistry, Hôpital Bichat-Claude Bernard, Paris, France

$\ddagger$ Department of Biochemistry, Hospital for Sick Children, Toronto, Canada

\Laboratoire d'Hygiene et Santé Publique, Faculté de Pharmacie, Paris, France

Correspondence to: Dr Cormier-Daire, cormier@necker.fr

1 Jaeken J, Matthijs G, Barone R, Carchon H. Carbohydrate-deficient glycoprotein (CDG) syndrome type I. f Med Genet 1997;34:73-6.

protein (CDG) syndrome type I. $\mathcal{F}$ Med Genet 1997;34:73-6.
2 Jaeken J. The carbohydrate-deficient glycoproteins syndrome: a genetic multisystemic disease with major nervous system involvement. Int Pediatr 1991;6:179.

3 First International Workshop on CDGS, Leuven, Belgium. Carbohydratedeficient glycoprotein syndromes become carbohydrate disorders of glycosylation: an updated nomenclature for CDG. Glycobiology (in press).

4 van Schaftingen E, Jaeken J. Phosphomannomutase deficiency is a cause of carbohydrate-deficiency glycoprotein syndrome type I. FEBS Lett 1995; 377:318-20
5 Niehues R, Hasilik M, Alton G, Körner C, Schiebe-Sukumar M, Koch HG, Zimmer KP, Wu R, Harms E, Reiter K, von Figura K, Freeze HH, Harms $\mathrm{HK}$, Marquardt T. Carbohydrate-deficient glycoprotein syndrome type Ib. Phosphomannose isomerase deficiency and mannose therapy. 7 Clin Invest 1998;101:1414-20

6 Korner C, Knauer R, Holzbach U, Hanefeld F, Lehle L, von Figura K. Carbohydrate-deficient glycoprotein syndrome type V: deficiency of dolichyl-P-Glc: Man9GlcNAc2-PP-dolichyl glucosyltransferase. Proc Natl Acad Sci USA 1998;95:13200-5.

7 Charuk J, Tan J, Bernardini M, Haddad S, Reithmeier R, Jaeken J, Schachter $\mathrm{H}$. Carbohydrate deficient glycoprotein syndrome type II, an autosomal recessive $\mathrm{N}$-acetylglucosaminyltransferase II deficiency different from typical hereditary multinuclearity with a positive acidified-serum lysis test (HEMPAS). Eur f Biochem 1995;230:797-805.

8 Jaeken J, Schatchter H, Carchon H, De Cock P, Coddeville B, Spik G. Carbohydrate-deficient glycoprotein syndrome type II: a deficiency in Golgi localized N-acetyl-glucosaminyltransferase II. Arch Dis Child 1994; 71:123-7.

9 Tan J, Dunn J, Jaeken J, Schachter H. Mutations in the MGAT2 gene controlling complex N-glycan synthesis cause carbohydrate-deficient glycoprotein syndrome type II, an autosomal recessive disease with defective brain development. Am f Hum Genet 1996;59:810-17.

10 Schachter H, Jaeken J. Carbohydrate-deficient glycoprotein syndrome type II. Biochim Biophys Acta 1999;1455:179-92.

11 Ramaekers VT, Stibler H, Kint J, Jaeken J. A new variant of the carbohydrate deficient glycoprotein syndrome. F Inherit Metab Dis 1991;14:385-8.

12 Seta N, Barnier A, Hochedez F, Besnard M, Durand G. Diagnostic value of Western blotting in carbohydrate-deficient glycoprotein syndrome. Clin Chim Acta 1996;254:131-40.

13 Van Eÿk HG, van Hoort WL, Dubelaar ML, van der Heul C. The microheterogeneity of human transferrins in biological fluids. Clin Chim Acta 1984;132:167-71.

\section{Characterisation of six large deletions in TSC2 identified using long range PCR suggests diverse mechanisms including Alu mediated recombination}

EDITOR-Tuberous sclerosis complex (TSC) is an autosomal dominant familial tumour syndrome (OMIM 19110 and 191092, http:/www.ncbi.nlm.nih.gov/omim/). It is characterised by the development of benign tumours (hamartomas), most frequently in the brain, skin, and kidneys. It is highly penetrant although with variable expression. In the majority of cases, there is significant neurological morbidity as seizures and mental retardation are common. Two causative genes for TSC have been identified, TSC1 and TSC2. ${ }^{12}$ Reports on mutation analysis in TSC show over 300 unique mutations with a varied spectrum. In cases where a mutation can be identified, approximately $80 \%$ have a TSC 2 mutation and $20 \%$ have a TSC1 mutation. All reported TSC1 mutations are small point mutations causing nonsense changes or splice site changes, or small insertions/deletions causing frameshift mutations. In TSC2, the majority (approximately 85\%) are small mutations (point mutations causing splice, nonsense, or missense changes, or small insertion/deletions). The remaining $15 \%$ of reported TSC 2 mutations are large deletions (ranging in size from $1 \mathrm{~kb}$ to $1 \mathrm{Mb}$ ). Other large rearrangements (inversions, insertions, translocations) have also been reported, but these account for $<1 \%$ of reported TSC2 mutations (http://zk.bwh.harvard.edu/ts). ${ }^{1-12}$

Because TSC is often a devastating disorder with a high frequency of sporadic cases, there is significant demand for genetic testing. Much progress has been made in detecting small mutations in TSC1 and TSC2 using a variety of techniques, such as heteroduplex (HD) analysis, single stranded conformation analysis (SSCP), protein truncation test (PTT), denaturing gradient gel electrophoresis (DGGE), and most recently denaturing high performance liquid chromatography (DHPLC). ${ }^{3568-11} 1314$ Although it is important for improving the overall mutation detection rate in TSC patients, there has been less effort to develop new techniques for identifying large deletions in TSC2, which make up a small but significant percentage of TSC2 mutations. Although screening for small mutations is the best initial strategy for detecting mutations in unknown cases, if a small mutation cannot be detected, the next approach should be screening for large TSC2 deletions. Southern blotting is currently the standard approach but unfortunately it has the disadvantage of requiring substantial quantities of DNA. Cytogenetics and fluorescence in situ hybridisation (FISH) are also standard techniques for detecting large deletions, but require either a fresh blood sample or cultured lymphocytes, and have other limitations.

Table 1 TSC2 long PCR primers

\begin{tabular}{|c|c|c|}
\hline $\begin{array}{l}\text { Base number } \\
\text { position }\end{array}$ & Location & Sequence $5^{\prime}>3^{\prime}$ \\
\hline \multicolumn{3}{|c|}{ Forward primers } \\
\hline $4672 \mathrm{~F}$ & 5'UTR & cattccttagctacaaaggcactactcctcc \\
\hline $8506 \mathrm{~F}$ & 5'UTR & tctttttctttcttggctcactacaacctcc \\
\hline $16432 \mathrm{~F}$ & 5'UTR & cctgagtacatagcaaagattgtcacgtcc \\
\hline $20805 \mathrm{~F}$ & 5'UTR & gagtggagagggctatttaaaacccatctg \\
\hline $25118 \mathrm{~F}$ & 5'UTR & gctgtagttgagttctcccagggagtg \\
\hline $28891 \mathrm{~F}$ & Intron 2 & agagtattgtcaatgagacaaaggaggtgagag \\
\hline $33093 \mathrm{~F}$ & Intron 6 & gtggagatgtagctcagggtggatgac \\
\hline $36910 \mathrm{~F}$ & Intron 9 & gtcgtcctggttttatagtgatgagctgc \\
\hline $39178 \mathrm{~F}$ & Exon 12 & cctccctcctgaacctgatctcctatagag \\
\hline $42770 \mathrm{~F}$ & Intron 15 & agcttgagaacctcctgagcataccagtag \\
\hline $46954 \mathrm{~F}$ & Intron 15 & ggttgggttttactttttgctgctgtg \\
\hline $49327 \mathrm{~F}$ & Intron 19 & ttcacctcacattcctggtgtgttacttg \\
\hline $52733 \mathrm{~F}$ & Intron 22 & cccettctcatctcaggtttaatcagtacatc \\
\hline $55586 \mathrm{~F}$ & Intron 25 & acgcctgttgggtctttccgag \\
\hline $60883 \mathrm{~F}$ & Intron 32 & gttctctttgggatggtcctttctagtcg \\
\hline $63753 \mathrm{~F}$ & Intron 37 & ctgagtgtctgtcaggagtaactggcaag \\
\hline \multicolumn{3}{|c|}{ Reverse primers } \\
\hline $21647 \mathrm{R}$ & 5'UTR & tgtagatgaccaaacatacccaaaccagac \\
\hline $25460 \mathrm{R}$ & Intron 1 & ctagcctagcaaagacacaggtagctcactc \\
\hline $33058 \mathrm{R}$ & Intron 6 & gactcctgaggctcagagagaccgag \\
\hline $38185 \mathrm{R}$ & Intron 10 & gagtagccacaactacaagcctttcttgc \\
\hline $42469 \mathrm{R}$ & Intron 15 & aggaaggttctgctgcctgctgag \\
\hline $45965 \mathrm{R}$ & Intron 15 & tatgacataaaagcaacatcccttcctcg \\
\hline $49637 \mathrm{R}$ & Exon 20 & gtaagagattaatgctgtcagcactggaacc \\
\hline $54565 \mathrm{R}$ & Intron 25 & atgcaacctttccaccctcgtc \\
\hline $60911 \mathrm{R}$ & Intron 32 & cgactagaaaggaccatcccaaagagaac \\
\hline $65432 \mathrm{R}$ & 3'UTR & cgcaccaagcagacaaagtcaataaaagag \\
\hline $74454 \mathrm{R}$ & 3'UTR & tgattctaagaggtgggttccctagagaaac \\
\hline $78956 \mathrm{R}$ & 3'UTR & gtaaactacatcgtcatgctgacatgtgc \\
\hline
\end{tabular}




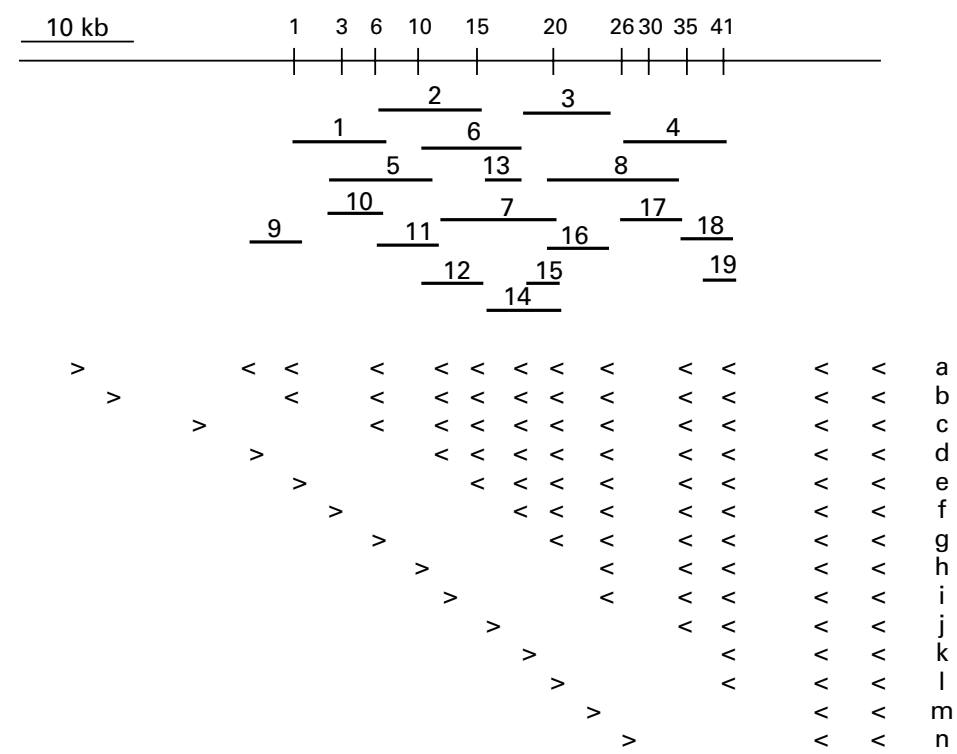

Figure 1 Positions of overlapping amplicons and primers used in long nested PCR. At the top, the genomic organisation of TSC2 is illustrated with the positions of selected exons indicated. The dark lines numbered 1-19 represent the $1.7 \mathrm{~kb}$ to $11.6 \mathrm{~kb}$ amplicons generated using standard long range PCR. The primer pairs for each amplicon are listed in table 2. The rows of arrowheads at the bottom represent the positions of primer combinations used for the 14 long nested multiplex reactions (labelled $a-n)$ ). Each row of primers represents a single PCR reaction in which a single forward primer ( $>$ ) is combined with multiple reverse primers $(<)$.

Long range PCR is an alternative method which has been used to identify large deletions and chromosome breakpoints in other disorders. ${ }^{15-18}$ The advantage of long range PCR is that it requires only small quantities of genomic DNA and standard PCR reagents. Also, if a mutation is detected by long range PCR, the sequence of the breakpoint fragments can then easily be determined for confirmation, in contrast to Southern blotting.

Here we describe a strategy for detecting large deletions in TSC2 using long range PCR and report six TSC cases with large deletions, all of which have been sequenced. These methods are important for both genetic testing purposes in TSC, and for the analysis of deletion junctions at the sequence level. This information on deletion junction sequences will help elucidate deletion mechanisms and might identify relative hotspots for these events. Furthermore, this long range PCR strategy is easily applied to other genes suspected of having large deletions.

DNA samples were collected from a series of 84 TSC patients who provided informed consent and met diagnostic criteria. ${ }^{19}$ A subset of 29 of these patients had no

Table 2 TSC2 long PCR primer combinations

\begin{tabular}{llllll}
\hline $\begin{array}{l}\text { Amplicon } \\
\text { No }\end{array}$ & $\begin{array}{l}\text { Base No } \\
\text { position forward }\end{array}$ & Location & $\begin{array}{l}\text { Base No } \\
\text { position reverse }\end{array}$ & Location & Size (bp) \\
\hline 1 & $25118 \mathrm{~F}$ & 5'UTR & $33058 \mathrm{R}$ & Intron 6 & 7941 \\
2 & $33093 \mathrm{~F}$ & Intron 6 & $42469 \mathrm{R}$ & Intron 15 & 9377 \\
3 & $46954 \mathrm{~F}$ & Intron 15 & $54565 \mathrm{R}$ & Intron 25 & 7612 \\
4 & $55586 \mathrm{~F}$ & Intron 25 & $65432 \mathrm{R}$ & 3'UTR & 9847 \\
5 & $28891 \mathrm{~F}$ & Intron 2 & $38185 \mathrm{R}$ & Intron 10 & 9295 \\
6 & $36910 \mathrm{~F}$ & Intron 9 & $45965 \mathrm{R}$ & Intron 15 & 9056 \\
7 & $39178 \mathrm{~F}$ & Exon 12 & $49637 \mathrm{R}$ & Exon 20 & 10460 \\
8 & $49327 \mathrm{~F}$ & Intron 19 & $60911 \mathrm{R}$ & Intron 32 & 11585 \\
9 & $20805 \mathrm{~F}$ & 5'UTR & $25460 \mathrm{R}$ & Intron 1 & 4656 \\
10 & $28891 \mathrm{~F}$ & Intron 2 & $33058 \mathrm{R}$ & Intron 6 & 4168 \\
11 & $33093 \mathrm{~F}$ & Intron 6 & $38185 \mathrm{R}$ & Intron 10 & 5093 \\
12 & $36910 \mathrm{~F}$ & Intron 9 & $42469 \mathrm{R}$ & Intron 15 & 5560 \\
13 & $42770 \mathrm{~F}$ & Intron 15 & $45965 \mathrm{R}$ & Intron 15 & 3196 \\
14 & $42770 \mathrm{~F}$ & Intron 15 & $49637 \mathrm{R}$ & Exon 20 & 6868 \\
15 & $46954 \mathrm{~F}$ & Intron 15 & $49637 \mathrm{R}$ & Exon 20 & 2684 \\
16 & $49327 \mathrm{~F}$ & Intron 19 & $54565 \mathrm{R}$ & Intron 25 & 5239 \\
17 & $55586 \mathrm{~F}$ & Intron 25 & $60911 \mathrm{R}$ & Intron 32 & 5326 \\
18 & $60883 \mathrm{~F}$ & Intron 32 & $65432 \mathrm{R}$ & 3'UTR & 4550 \\
19 & $63753 \mathrm{~F}$ & Intron 37 & $65432 \mathrm{R}$ & 3'UTR & 1680 \\
\hline
\end{tabular}

evidence of a small mutation in TSC1 or TSC2 by single exon amplification and mutational screening, and were screened in this study for large deletions in TSC2 using long range PCR. DNA was extracted from white blood cells or EBV transformed lymphoblastoid cell lines using standard methods. An additional six samples suspected of having genomic rearrangements based on Southern blot abnormalities were also screened using long range PCR.

Long range PCR primers were designed using the primer design program of the Wisconsin Package (Genetics Computer Group), and chosen to be $22-33$ bp in length with melting temperatures of $68-69^{\circ} \mathrm{C}$. A series of 16 forward primers and 12 reverse primers were selected and spaced across the TSC2 genomic region (Genbank AC005600) at 2.8-9 kb intervals. Primer sequences and positions are shown in table 1 . A series of 19 primer pairs (fig 1, table 2) were used in standard long range PCR. In addition, long nested multiplex PCR was performed using single forward primers and a series of reverse primers (fig 1 and fig 2C). All long PCR reactions were done in a volume of $25 \mu \mathrm{l}$ using the LA PCR kit (TaKaRa). Each reaction contained 50-250 ng genomic DNA as template, 0.2 $\mu \mathrm{mol} / 1$ of all primers, and $400 \mu \mathrm{mol} / 1 \mathrm{dNTP}$. PCR cycling was done on a MJ Research PTC-100 thermal cycler for 32 cycles at $94^{\circ} \mathrm{C}$ for one minute, $98^{\circ} \mathrm{C}$ for 20 seconds, and $68^{\circ} \mathrm{C}$ for 15 minutes, followed by a final extension at $72^{\circ} \mathrm{C}$ for five minutes. Products were analysed on standard $0.8 \%$ agarose gels and stained with ethidium bromide. Agarose gels were run slowly (25-35 volts) for 24 hours at room temperature so that the bands of large amplicons $(8-10 \mathrm{~kb})$ were sharp. They were examined after electrophoresing for three to five hours and again after 24 hours. At three to five hours, the presence of all amplicons could be observed and the sizes of smaller amplicons (500 bp-2 kb) determined. The 24 hour time point allowed the detection of small (around $1 \mathrm{~kb}$ ) size differences in the larger amplicons.

In cases where there was evidence for a large deletion, the aberrant PCR amplicon generated using long range PCR and containing the deletion was then purified using a Qiagen gel purification column following the manufactur- 


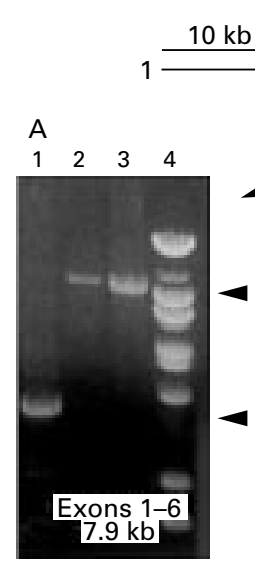

Patient 1 $4.5 \mathrm{~kb}$ deletion Intron 2-intron 5 $\begin{array}{llllllllll}1 & 3 & 6 & 10 & 15 & 20 & 26 & 30 & 35 & 41\end{array}$

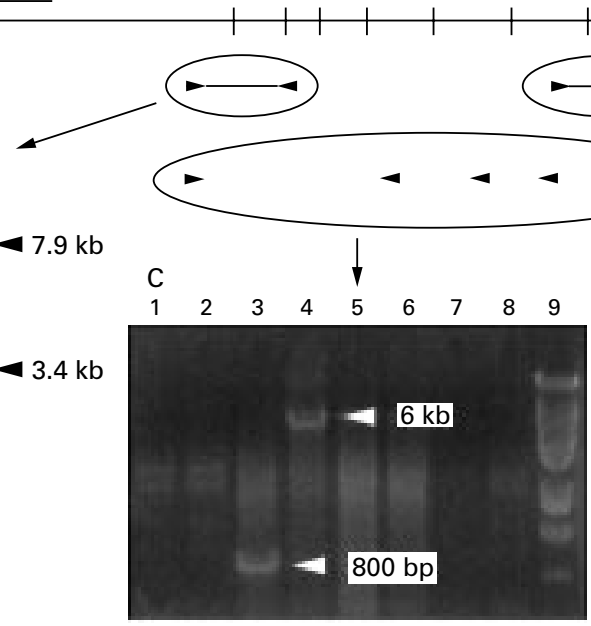

Patients 2 and 3

34 and $39 \mathrm{~kb}$ deletions

Nested multiplex PCR
79586

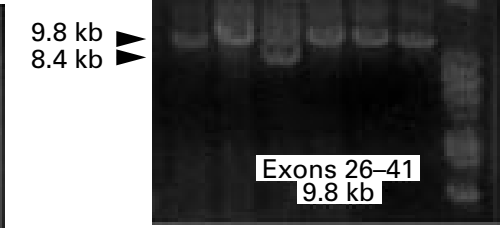

Patient 4

$1.4 \mathrm{~kb}$ deletion

Exon 37-exon 39

Figure 2 Examples of deletions in TSC2 detected using long range PCR. At the top is a diagram of the genomic organisation of selected exons in the TSC2 gene. It represents 79586 base pairs of genomic sequence (Genbank AC005600). Below are the positions of selected primers which were useful for detecting four of the deletions described in this paper. Panel $A$ shows a deletion in patient 1 detected with primers $25118 F / 5$ 'UTR and 33053R/intron 6 which amplify exons 1-6. These primers should amplify a $7.9 \mathrm{~kb}$ band as illustrated by control samples in lanes 2 and 3, but in lane 1 the patient sample contains a $4.5 \mathrm{~kb}$ deletion between intron 2 and intron 5 so a smaller $3.4 \mathrm{~kb}$ band was amplified. In that patient there is only a very weak band at $7.9 \mathrm{~kb}$ representing the normal allele, reflecting the inferior amplification of the longer fragment in that sample. Panel B shows a deletion in patient 4 detected with primers $55586 F /$ intron 25 and 65432R/3'UTR which amplify exons 26-41. These primers should amplify a 9.8 kb band as shown in control lanes 1, 2, 4, 5 , and 6, but lane 3 illustrates a patient with a $1.4 \mathrm{~kb}$ deletion in which both a $9.8 \mathrm{~kb}$ band and an $8.4 \mathrm{~kb}$ band can be seen. Panel $C$ shows two examples of deletions in TSC2 detected using the nested multiplex reaction. This agarose gel shows eight patient samples amplified using a single forward primer $\left(25118 \mathrm{~F} / 5^{\prime} \mathrm{UTR}\right)$ and a collection of five reverse primers (42469R/intron 15, 49637R/exon 20, 54565R/intron 25, 60911R/intron 32, 65432R/3'UTR) in a long nested multiplex reaction. In this long nested multiplex reaction, an $800 \mathrm{bp}$ amplicon is observed in lane 3 (patient 2) and a $6 \mathrm{~kb}$ amplicon in lane 4 (patient 3) as indicated by the arrows. The presence of any band in this reaction indicates that a deletion in

TSC2 is present. Normally there is no amplification as shown in lanes 1-2 and 5-8. The faint bands which appear in lanes 1-2 and the smear in lanes 5-6 were interpreted as non-specific PCR artefact which is observed in some samples but easily distinguished from reproducible amplification of an aberrant band when a deletion is present. DNA size standards (lambda BSTEII digest from New England Biolabs) are shown in panel A lane 4, panel B lane 7, and panel C lane 9.

er's protocol. The purified amplicon was sequenced directly or used as a template for amplifying individual TSC2 exons to determine the precise location of the deletion. Primer sequences for PCR amplification of individual TSC2 exons can be found at http://zk.bwh.harvard.edu/ projects/tsc/. PCR was performed using Amplitaq ${ }^{\circledR}$ Gold (Perkin Elmer); $20 \mu \mathrm{l}$ reactions were used with $1 \mu \mathrm{l}$ of gel purified PCR product as template, $1.0 \mu \mathrm{mol} / 1$ of each primer, $10 \mathrm{mmol} / 1$ of dNTPs, $0.2 \mu \mathrm{l}$ of Amplitaq ${ }^{\circledR}$ gold polymerase (Perkin Elmer), and the manufacturer's recommended buffers. PCR cycling was carried out on an MJ Research PTC-100 thermal cycler using $95^{\circ} \mathrm{C}$ for 12 minutes, followed by 35 cycles of $94^{\circ} \mathrm{C}$ for 30 seconds, $55-60^{\circ} \mathrm{C}$ (depending on the exon) for 30 seconds for annealing, $72^{\circ} \mathrm{C}$ for 45 seconds for extension, and a final extension step at $72^{\circ} \mathrm{C}$ for four minutes.

The deletion junctions of all six cases were sequenced. The region of the junction was narrowed down by a combination of direct sequencing as well as results of short PCR amplification of individual exons. In some cases, amplification of the junctions was repeated using internal primers. Automated sequencing was done using an ABI 377 machine (Perkin Elmer) with Big Dye terminator chemistries (Perkin Elmer). Sequence traces were analysed using Sequencher (Gene Codes).

We have developed a PCR based assay for detecting large deletions in TSC2. Initially, we designed four primer pairs for amplifying all exons of TSC2 in fragments ranging from 7.6-9.8 kb with no overlap (amplicons 1-4 in fig 1, table 2). In a pilot study, we analysed a subset of TSC patient samples not yet found to harbour small TSC2 mutations and identified one large deletion $(4.5 \mathrm{~kb}$, patient 1$)$. With these four primer pairs, any deletions spanning a primer position would be missed as only the normal allele would amplify. In order to increase the probability of finding all deletions, we designed additional primers for amplifying overlapping segments of the TSC2 gene. Primers were positioned 2.8-9 $\mathrm{kb}$ apart over the span of the TSC 2 gene in both directions. As all primers had melting temperatures of $68-69^{\circ} \mathrm{C}$ and all PCR reactions were done using identical cycling conditions (table 1), different combinations of primers could be used to yield overlapping amplicons of different sizes. After testing all primers for PCR, we expanded our assay to included the amplification of a total of 19 overlapping fragments ranging in size from 1.7-11.6 kb (fig 1, table 2). The smaller sized amplicons (1.7-5.5 kb) were included because smaller deletions of $500 \mathrm{bp}-1 \mathrm{~kb}$ would be more easily detected in smaller amplicons.

Because the standard PCR described above would limit the detection of deletions to those ranging in size from 500 bp to $10 \mathrm{~kb}$, we predicted that larger deletions could be identified if each forward primer was combined with a reverse primer far enough away such that amplification would only occur in the presence of a large deletion. Because the extension time for PCR cycling was 15 minutes, we estimated that primers spaced $>15 \mathrm{~kb}$ apart would not produce an amplicon unless there was a deletion present. Rather than performing up to 12 individual PCR reactions with each forward primer and each different reverse primer, we included multiple reverse primers in nested multiplex reactions with a single forward primer, as illustrated in fig 1 . This significantly reduced the number of 
Table 3 Positions of six TSC2 deletions

\begin{tabular}{lll}
\hline Patient & Deletion & Features \\
\hline 1 & $4.5 \mathrm{~kb}$ deletion intron 2-intron 5 & Alu mediated \\
2 & 39 kb deletion intron 1-intron 40 & 11 bp insertion at junction \\
3 & $34 \mathrm{~kb}$ deletion intron 1-exon 33 & $3 \mathrm{bp}$ overlap at junction \\
4 & $1.4 \mathrm{~kb}$ deletion exon 37-exon 39 & $6 \mathrm{bp}$ insertion at junction \\
5 & $1.3 \mathrm{~kb}$ deletion intron 19-intron 20 & $3 \mathrm{bp}$ overlap at junction \\
6 & $10.1 \mathrm{~kb}$ deletion intron 9-intron 15 & Alu mediated \\
\hline
\end{tabular}

PCR reactions per sample, thereby improving the efficiency of the assay and reducing costs. We did a series of 14 nested multiplex reactions on all samples. In this series, a PCR amplification was performed with a single forward primer and a series of two to 12 reverse primers. All forward primers listed in table 1 were used in a nested multiplex reaction except $60883 \mathrm{~F}$ and $63753 \mathrm{~F}$. In each case, the closest reverse primer was positioned $>15 \mathrm{~kb}$ away to ensure that a PCR product would amplify only if a deletion was present in the TSC2 gene.

We tested this long PCR strategy on a subset of a collection of 84 TSC patient samples with unknown mutations which were being investigated for TSC1 and TSC 2 mutations. In this collection, 29/84 patients did not have evidence of a small mutation in TSC1 or TSC2 after analysis by DHPLC. ${ }^{1320}$ Four of these samples (patients 1-4) were found to have large deletions using our long PCR assay (fig 2, table 3). In two cases, standard PCR detected a smaller than expected band. In patient 1 , using primers $25118 \mathrm{~F} /$ 5'UTR and 33058R/intron 6 amplified a $3.4 \mathrm{~kb}$ band rather than the expected $7.9 \mathrm{~kb}$ band (fig $2 \mathrm{~A}$ ). In patient 4 , primers $55568 \mathrm{~F} /$ intron 25 and $65432 \mathrm{R} / 3$ 'UTR amplified both the normal $9.8 \mathrm{~kb}$ band representing the normal allele as well as an $8.4 \mathrm{~kb}$ band (fig $2 \mathrm{~B}$ ). In the other two cases (patients 2 and 3), nested multiplex reactions using $25118 \mathrm{~F} / 5$ 'UTR with five reverse primers (42469R/intron 15, 49637R/exon 20, 54565R/intron 25, 60911R/intron 32, 65432R/3'UTR) amplified aberrant products suggesting a deletion in TSC2 was present (fig 2C). In these cases, repeat standard PCR was performed with primers $25118 \mathrm{~F} / 5^{\prime} \mathrm{UTR}$ and $65432 \mathrm{R} /$ 3'UTR which verified the result and determined the size and location of the deletion.

To investigate further the usefulness of this strategy, we obtained six TSC samples from another lab (AV) which were suspected of having large deletions or other rearrangements based on Southern blotting results. One of these (patient 5) has been described previously ${ }^{2122}$ and the others were not fully characterised. In this series, two deletions were identified and their sequences determined. In one case, primers 49327F/intron 19 and 54565R/intron 25 amplified both the expected $5.2 \mathrm{~kb}$ band as well as a smaller $3.9 \mathrm{~kb}$ band suggesting a $1.3 \mathrm{~kb}$ deletion (patient 5 ). In the other case, the nested multiplex reaction using primer 33093F/intron 6 and several reverse primers (49637R/exon 20, 54565R/intron 25, 60911R/intron 32, 65432R/3'UTR, 74454R/3'UTR and $78956 \mathrm{R} / 3^{\prime} \mathrm{UTR}$ ) showed an aberrant $6.4 \mathrm{~kb}$ band suggesting a deletion was present. Repeat standard PCR using primers $33093 \mathrm{~F} /$ intron 6 and $49637 \mathrm{R} /$ exon 20 also resulted in a 6.4 $\mathrm{kb}$ amplicon consistent with a $10.1 \mathrm{~kb}$ deletion (patient 6). Of these six cases, one was suspected to have an insertion and another was subsequently found to have a translocation involving the TSC2 gene, ${ }^{23}$ neither of which were detected using long range PCR.

All six deletions were characterised at the sequence level. A combination of short PCR of intervening exons and
Patient 1 Intron 2 Intron 5

Patient 2 Intron 1

11 bp insertion

Intron 40/Exon 41

Patient 3

Intron 1

Exon 33

Patient 4

Intron 36/Exon 37

6 bp insertion

Exon 39/Intron 39

Patient 5

Intron 19

Intron 20/Exon 21

Patient 6

Intron 9

Intron 15

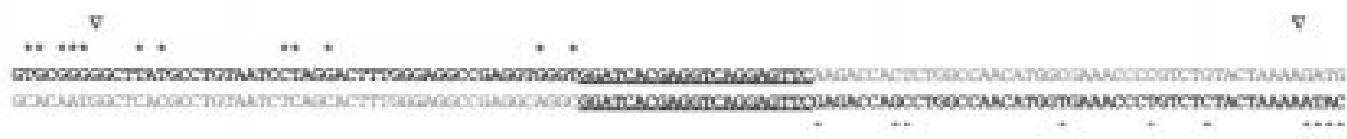

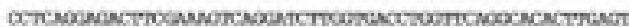

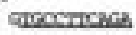

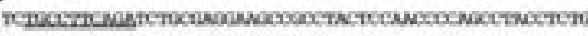
-kane 41 begins

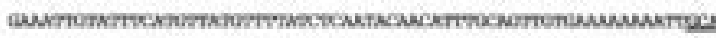

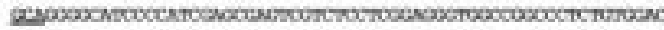

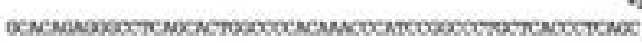

Inon 17 beqine

arrac

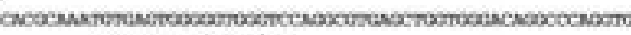
+Intzon 19 tagian.

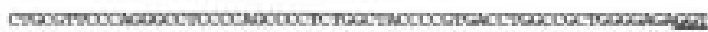

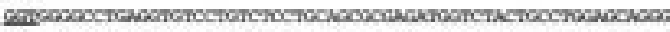
+lane 21 tegias

$\nabla$

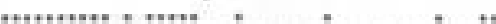

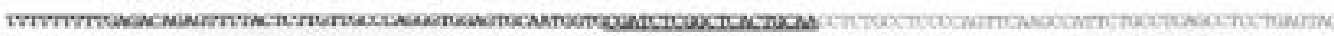

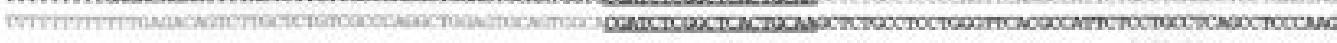

Figure 3 Sequences of TSC2 deletion junctions. Patient 1: deletion junction between Alu repetitive sequences within intron 2 and intron 5. There are 110 bp of highly homologous sequence (88\%) between the open triangles. The join occurs within the underlined sequence. Sequence shown in grey is the adjacen homologous sequences which are deleted. The asterisks show the mismatched sequences on the left arm and the carets show the mismatched sequences on the right arm. Patient 2: deletion junction between intron 1 and intron 40. There is an 11 bp insertion at the junction, the 10 underlined bases

(GTGCCTTCAGA) in the insertion are repeated in intron 40 near the junction (also underlined). Patient 3: there is a 3 bp overlap (GCA) at the site of this deletion junction between intron 1 and exon 33. Patient 4: there is a 6 bp insertion (GTTTTC) between the deletion connecting exon 37 with exon 39. This small insertion is not repeated near deletion junction site. Patient 5: there is a 3 bp overlap (GGT) at the site of this deletion junction between intron 19 and intron 20. Patient 6: deletion junction between Alu repetitive sequences within intron 9 and intron 15. There are 88 bp of highly homologous sequence (88\%) near the junction between the open arrows. The join occurs within the underlined sequence. The asterisks show the mismatched sequences on the left arm and the carets show the mismatched sequences on the right arm. 
sequencing was used to narrow down the location of each deletion junction. Sequences of all six deletion junctions are shown in fig 3. In two cases, the deletions occurred within homologous Alu repeats (patient 1 and patient 6). Although Alu mediated recombination has been described in disease causing rearrangements in other disorders, this has not been reported previously for TSC2. In another two cases, there was a $3 \mathrm{bp}$ overlap at the site of the junction, GCA in patient 3 and GGT in patient 5 . In patient 2, there was an $11 \mathrm{bp}$ insertion at the junction and 10 of these base pairs (TGCCTTCAGA) are identical to sequence found a few base pairs away in the intron 40 arm of the junction. In the last case (patient 4), there was a $6 \mathrm{bp}$ insertion (GTTTC) at the junction with no apparent homology to either end. These results suggest there are diverse mechanisms causing deletions in the TSC2 gene.

We have developed a useful strategy using long range PCR to identify large deletions ranging in size from $1.3 \mathrm{~kb}$ to $39 \mathrm{~kb}$ in the TSC 2 gene. Because of the known mutation spectrum in TSC, ${ }^{1-12}$ it is most appropriate to analyse new samples for small mutations in TSC2 and TSC1 before using this assay. We used our long range PCR assay for mutation analysis in a set of 29/84 samples not found to have small TSC2 or TSC1 mutations by DHPLC or HD analysis of amplified exons. Using the long PCR method, we detected large deletions in $4 / 84$ or $4.8 \%$. This compares with the wide range of reported frequencies for large deletions in the TSC2 gene: 24 of 163 patients (15\%) had large deletions when screened by several methods, but only 11 of $163(7 \%)$ would be small enough to be detected by this long PCR method ${ }^{3}$; 0/140 patients screened by Southern blot analysis ${ }^{24}$; and two of 88 patients $(2 \%)$ screened by Southern blot analysis. ${ }^{25}$ If these three large studies are combined, $13 / 391$ patients $(3.3 \%)$ were found to have deletions in the $500 \mathrm{bp}$ to $79 \mathrm{~kb}$ range. Thus, we suspect that our method is capable of detecting most deletions that occur between the primers used here. Clearly, it would fail to detect deletions that extend beyond these primers, many of which have been described, ${ }^{1}$ as well as translocations, most large insertions, and more complex genomic rearrangements, which appear rare $(<1 \%)$ in TSC $2 .{ }^{323}$ Another class of deletions that would be missed by this strategy are those that are intermediate in size (50-500 $\mathrm{bp}$ ), which would often be missed by both single exon amplification strategies and deletion scanning by long range PCR or Southern blot analysis. These have yet to be reported in TSC2.

In this report we provide the first identification of TSC2 deletion junction sequences (fig 3 ). Our results suggest that several mechanisms of deletion occur in this gene. In two cases (patients 1 and 6) Alu mediated homologous recombination occurred. Such Alu and LINE mediated rearrangements are well known for many disease genes, ${ }^{26-32}$ but have not yet been reported for TSC2. In these two cases, homologous Alu repeats are present in the introns which are inappropriately joined. In patient 1 , there are $110 \mathrm{bp}$ of sequence with $88 \%$ homology in the region of the recombination. In patient 6 , there are $74 \mathrm{bp}$ of homologous sequence with $88 \%$ homology flanking the deletion site. Rudiger et $a^{33}$ described a $26 \mathrm{bp}$ core sequence (5' - CCTGTAATCCCAGCACTTTGGGAGGC - 3') which was at or very close to the junction sites of several Alu mediated LDL receptor gene deletions. Although copies of this $26 \mathrm{bp}$ sequence are found within the introns at these deletions, they are at some distance $(>250 \mathrm{bp}$ ) from the junction sites so it is not clear whether they played a role in the recombination process. It is also notable that all four introns involved in the Alu mediated deletions in TSC2 contain poly $\mathrm{T}$ or poly A tracts or both flanking the Alu repeat, at distances less than $400 \mathrm{bp}$ away. Flanking poly
$\mathrm{A} / \mathrm{T}$ tracts have been identified in Alu mediated deletions in the Fanconi A gene. ${ }^{34} 35$

The deletion junctions in the remaining four patients were diverse. There are two cases (patients 3 and 5) in which there is a $3 \mathrm{bp}$ overlap at the junction. A similar $3 \mathrm{bp}$ overlap has also been observed in an $\alpha$ globin mutation, but the mechanism for the illegitimate recombination is not well understood. ${ }^{28}$ In the last two cases (patients 2 and 4 ) there are small insertions at the junction. In patient 4 , there is a $6 \mathrm{bp}$ insertion (GTTTC) with no homology to either arm of the junction. It is interesting to note that this insertion contains GTT which is commonly found at topoisomerase I cleavage sites. ${ }^{36}$ In patient 2 , the $10 \mathrm{bp}$ of the 11 bp insertion between intron 1 and intron 40 are identical to a $10 \mathrm{bp}$ (GTGCCTTCAGA) stretch in intron 40 close to the deletion site. In addition, the $11 \mathrm{bp}$ insertion contains CTT which is another sequence commonly found at topoisomerase I cleavage sites. ${ }^{36} \mathrm{~A}$ small insertion at the site of a deletion has also been described in a $20.7 \mathrm{~kb}$ factor VIII gene deletion. ${ }^{16}$ Defining the deletion junctions of a larger number of TSC2 deletion cases may be helpful, but based upon present observations several mechanisms of deletions occur in TSC2 without a regional hot spot.

The major advantages of this long PCR approach are that it is simple, requires no special reagents or laboratory equipment, and can be performed on small quantities of genomic DNA, which is easily stored for long periods of time. Furthermore, the sequence of the deletion junction can be determined once an aberrant PCR amplicon is generated, to provide final confirmation that a mutation has been detected. Although we detected a deletion as small as $1.3 \mathrm{~kb}$ in this study, we suspect that deletions as small as $500 \mathrm{bp}$ could be detected. The largest deletion detected here was 39 $\mathrm{kb}$, but theoretically deletions as large as approximately 70 $\mathrm{kb}$ could be detected with the primers reported here. With effort in designing additional primers, it is possible that larger deletions could be identified using this method.

The disadvantages of this long PCR strategy is that it is not automated and to analyse each sample requires 33 individual PCR reactions. Although any false positive PCR results would quickly be eliminated after sequencing data were obtained, a false negative could go undetected. Because the PCR failure rate can be as high as $20-30 \%$, it is important always to include positive controls in each PCR set. Another disadvantage is that although long PCR might detect some insertions, it would not detect translocations or inversions, none of which appear to be common in TSC2 but have been reported. ${ }^{323}$ It is likely that many insertions would not be detected because amplification of the shorter normal allele would be favoured during PCR. Although other new methods such as spectral karyotyping, ${ }^{37}$ dynamic molecular combing, ${ }^{38}$ or quantitative $\mathrm{PCR}^{27}{ }^{39}$ may ultimately prove to be more powerful for detecting large deletions and other large rearrangements, they have been used on a limited number of genes and have not been tested in large numbers of samples with unknown mutations. Furthermore, these methods are not widely used and all require access to expensive, specialised equipment.

Although large deletions in the human genome are not as common as single nucleotide polymorphisms, ${ }^{40}{ }^{41}$ they make a significant contribution to deleterious mutations and for some genes are the most frequent mutation type. In Duchenne muscular dystrophy, large deletions account for $65 \%$ of mutations. ${ }^{39}$ In the Fanconi anaemia group A gene, $40 \%$ of mutations identified in a set of 26 patients were large intragenic deletions. ${ }^{27}$ It has been reported that large deletions account for $36 \%$ of all BRCA1 mutations including two important founder mutations in a Dutch population of breast cancer families in which a BRCA1 mutation was identified. ${ }^{29}$ As it is generally difficult to assay 
for all possible deletions, it is quite likely that large deletions and other rearrangements may be underreported and may account for a significant percentage of subjects with linkage to certain genes but in which no mutation has been identified. For instance, it has been suggested that large rearrangements may explain a substantial fraction of the $37 \%$ of breast/ovarian cancer families which show linkage to the BRCA1 gene but for whom no mutation has been identified. ${ }^{30}$ Undetected deletions may contribute to the $20-30 \%$ of TSC patients in which no TSC1 or TSC 2 mutation can be identified, ${ }^{3}$ although there are several other reasons for failure of mutation identification in TSC.

We thank Joon Chung for assistance with sequencing and Edward Jung for technical assistance. We also thank the TSC patients and their families for contributing blood samples or financial support for this project. This work was supported by NIH grants CA71445 (SD), NS 31535 (DK), and the National Tuberous by NIH grants CA71445 (SD), NS 31535 (DK), and the National Tuberous
Sclerosis Association. Internet resources: <http://zk.bwh.harvard.edu/ts $><$ http:// Sclerosis Association. Internet resources: $<$ http://zk.bwh.harvard.edu/ts $>$
zk.bwh.harvard.edu/projects/tsc/ $><$ http://www.ncbi.nlm.nih.gov/omim/ $>$

S L DABORA*†

A A NIETO*

D FRANZ

S JOZWIAKS

A VAN DEN OUWELAND
D J KWIATKOWSKI ${ }^{\star} \dagger$

${ }^{\star}$ Division of Hematology, Brigham and Women's Hospital, 221 Longwood Avenue, LMRC 301, Boston, MA 02115, USA

†Harvard Medical School, Boston, MA 02115, USA

$\ddagger$ Division of Pediatric Neurology, Children’s Hospital Medical Center, Cincinnati, OH, USA

§Department of Child Neurology, Children's Memorial Hospital, Warsaw,

Poland

|Department of Clinical Genetics, Erasmus University and University

Hospital, 3015 GE Rotterdam, The Netherlands

Correspondence to: Dr Dabora or Dr Kwiatkowski,

sdabora@rics.bwh.harvard.edu ordk@zk.bwh.harvard.edu

1 Consortium ECTS. Identification and characterization of the tuberous sclerosis gene on chromosome 16. Cell 1993;75:1305-15.

2 van Slegtenhorst M, de Hoogt R, Hermans C, Nellist M, Janssen B, Verhoef S, Lindhout D, van den Ouweland A, Halley D, Young J, Burley M, Jeremiah S, Woodward K, Nahmias J, Fox M, Ekong R, Osborne J, Wolfe J, Jeremiah S, Woodward K, Nahmias J, Fox M, Ekong R, Osborne J, Wolfe J, Povey S, Snell RG, Cheadle JP, Jones AC, Tachataki M, Ravine D,
Kwiatkowski DJ. Identification of the tuberous sclerosis gene TSC1 on Kwiatkowski DJ. Identification of the tuber
chromosome 9q34. Science 1997;277:805-8.

3 Jones AC, Shyamsundar MM, Thomas MW, Maynard J, Idziaszczyk S, Tomkins S, Sampson JR, Cheadle JP. Comprehensive mutation analysis of TSC 1 and TSC2 and phenotypic correlations in 150 families with tuberous sclerosis. Am F Hum Genet 1999;64:1305-15.

4 Sampson JR, Maheshwar MM, Aspinwall R, Thompson P, Cheadle JP, Ravine D, Roy S, Haan E, Bernstein J, Harris PC. Renal cystic disease in tuberous sclerosis: role of the polycystic kidney disease 1 gene. Am $\mathcal{7} \mathrm{Hum}$ Genet 1997;61:843-51.

5 van Bakel I, Sepp T, Ward S, Yates JR, Green AJ. Mutations in the TSC2 gene: analysis of the complete coding sequence using the protein truncation test (PTT). Hum Mol Genet 1997;6:1409-14

6 Au KS, Rodriguez JA, Finch JL, Volcik KA, Roach ES, Delgado MR, Rodriguez E Jr, Northrup H. Germ-line mutational analysis of the TSC2 gene
in 90 tuberous-sclerosis patients. Am f Hum Genet 1998;62:286-94.

7 Jones AC, Daniells CE, Snell RG, Tachataki M, Idziaszczyk SA, Krawczak M, Sampson JR, Cheadle JP. Molecular genetic and phenotypic analysis M, Sampson JR, Cheadle JP. Molecular genetic and phenotypic analysis
reveals differences between TSC1 and TSC2 associated familial and reveals differences between TSC1 and TSC2 associated

8 Beauchamp RL, Banwell A, McNamara P, Jacobsen M, Higgins E, Northrup H, Short P, Sims K, Ozelius L, Ramesh V. Exon scanning of the entire TSC2 gene for germline mutations in 40 unrelated patients with tuberous sclerosis. Hum Mutat 1998;12:408-16.

9 Niida Y, Lawrence-Smith N, Banwell A, Hammer E, Lewis J, Beauchamp RL, Sims K, Ramesh V. Analysis of both TSC1 and TSC2 for germline mutations in 126 unrelated patients with tuberous sclerosis. Hum Mutat 1999;14:412-22.

10 Young JM, Burley MW, Jeremiah SJ, Jeganathan D, Ekong R, Osborne JP, Povey S. A mutation screen of the TSC1 gene reveals 26 protein truncating mutations and 1 splice site mutation in a panel of 79 tuberous sclerosis patients. Ann Hum Genet 1998;62:203-13.

11 Kwiatkowska J, Jozwiak S, Hall F, Henske EP, Haines JL, McNamara P, Braiser J, Wigowska-Sowinska J, Kasprzyk-Obara J, Short MP, Kwiatkowski DJ. Comprehensive mutational analysis of the TSC1 gene: observations on frequency of mutation, associated features, and nonpenobservations on frequency of mutation,
etrance. Ann Hum Genet 1998;62:277-85.

12 van Slegtenhorst $M$, Verhoef S, Tempelaars A, Bakker L, Wang Q, Wessels $M$, Bakker R, Nellist M, Lindhout D, Halley D, van den Ouweland A. Mutational spectrum of the TSC1 gene in a cohort of 225 tuberous sclerosis complex patients: no evidence for genotype-phenotype correlation. $\mathcal{f}$ Med Genet 1999;36:285-9.

13 Choy Y, Dabora S, Hall F, Ramesh V, Niida Y, Franz D, Kasprzyk-Obara J, Reeve M, Kwiatkowski DJ. Superiority of denaturing high performance liquid chromatography over single-stranded conformation and conformationsensitive gel electrophoresis for mutation detection in TSC2. Ann Hum Genet 1999;63:383-91.
14 Dabora SL, Sigalas I, Hall F, Eng C, Vijg J, Kwiatkowski DJ. Comprehensive mutation analysis of TSC1 using two-dimensional DNA electrophoresis with DGGE. Ann Hum Genet 1998;62:491-504.

15 Thomas R, McConnell R, Whittacker J, Kirkpatrick P, Bradley J, Sandford $\mathrm{R}$. Identification of mutations in the repeated part of the autosomal dominant polycystic kidney disease type 1 gene, PKD1, by long-range PCR. Am f Hum Genet 1999;65:39-49.

16 Van de Water N, Williams R, Ockelford P, Browett P. A $20.7 \mathrm{~kb}$ deletion within the factor VIII gene associated with LINE-1 element insertion. Thromb Haemostas 1998;79:938-42.

17 Watnick TJ, Piontek KB, Cordal TM, Weber H, Gandolph MA, Qian F, Lens XM, Neumann HP, Germino GG. An unusual pattern of mutation in the duplicated portion of PKD1 is revealed by use of a novel strategy for the duplicated portion of PKD1 is revealed by use of
mutation detection. Hum Mol Genet 1997;6:1473-81.

18 Luthra R, Pugh WC, Waasdorp M, Morris W, Cabanillas F, Chan PK, Sarris AH. Mapping of genomic $\mathrm{t}(2 ; 5)(\mathrm{p} 23 ; \mathrm{q} 35)$ break points in patients with anaplastic large cell lymphoma by sequencing long-range PCR products. Hematopathol Mol Hematol 1998;11:173-83.

19 Roach ES, Gomez MR, Northrup H. Tuberous sclerosis complex consensus conference: revised clinical diagnostic criteria. $\mathcal{F}$ Child Neurol 1998;13:624-8.

20 Dabora S, Roberts PS, Nieto AA, Chung J, Choy Y, Thiele E, Franz D, Egelhoff J, Jozwiak S, Kasprzyk-Obara J, Kwiatkowski DJ. Genotype/phenotype analysis in 224 TSC patients indicates increased severity of TSC2 disease analysis in 224 TSC patients indicates increased severity of TSC

21 Verhoef S, Bakker L, Tempelaars AM, Hesseling-Janssen AL, Mazurczak T, Jozwiak S, Fois A, Bartalini G, Zonnenberg BA, van Essen AJ, Lindhout D, Halley DJ, van den Ouweland AM. High rate of mosaicism in tuberous sclerosis complex. Am F Hum Genet 1999;64:1632-7.

22 Verhoef S, Vrtel R, van Essen T, Bakker L, Sikkens E, Halley D, Lindhout $\mathrm{D}$, van den Ouweland A. Somatic mosaicism and clinical variation in tuberous sclerosis complex. Lancet 1995;345:202.

23 Eussen BHJ, Bartalini G, Bakker L, Balestri P, Di Lucca C, Van Hemel JO, Dauwerse H, van den Ouweland AMW, Ris-Stalpers C, Verhoef S, Halley DJJ, Fois A. An unbalanced translocation t $(8 ; 16) \mathrm{g} 24.3 ; \mathrm{p} 13.3)$ pat. DJJ, Fois A. An unbalanced translocation t(8;16)g24.3;p 13.3)pat. associated with tuberous sclerosis complex, adult polycys
and hypomelanosis of Ito. $\mathcal{7}$ Med Genet $2000 ; 37: 287-91$.

24 Verhoef S, Vrtel R, Bakker L, Stolte-Dijkstra I, Nellist M, Begeer JH, Zaremba J, Jozwiak S, Tempelaars AM, Lindhout D, Halley DJ, van den Ouweland AM. Recurrent mutation 4882delTT in the GAP-related domain of the tuberous sclerosis TSC2 gene. Hum Mutat 1998;suppl:S85-7

25 Au KS, Rodriguez JA, Rodriguez E Jr, Dobyns WB, Delgado MR, Northrup $\mathrm{H}$. Mutations and polymorphisms in the tuberous sclerosis complex gene on chromosome 16. Hum Mutat 1997;9:23-9.

26 Harteveld KL, Losekoot M, Fodde R, Giordano PC, Bernini LF. The involvement of Alu repeats in recombination events at the alpha-globin gene cluster: characterization of two alphazero-thalassaemia deletion breakpoints. Hum Genet 1997;99:528-34.

27 Morgan NV, Tipping AJ, Joenje H, Mathew CG. High frequency of large intragenic deletions in the Fanconi anemia group A gene. Am f Hum Genet 1999;65:1330-41.

28 Nicholls RD, Fischel-Ghodsian N, Higgs DR. Recombination at the human alpha-globin gene cluster: sequence features and topological constraints. Cell 1987;49:369-78.

29 Petrij-Bosch A, Peelen T, van Vliet M, van Eijk R, Olmer R, Drusedau M, Hogervorst FB, Hageman S, Arts PJ, Ligtenberg MJ, Meijers-Heijboer H, Klijn JG, Vasen HF, Cornelisse CJ, van't Veer LJ, Bakker E, van Ommen Klijn JG, Vasen HF, Cornelisse CJ, van't Veer LJ, Bakker E, van Ommen
GJ, Devilee P. BRCA1 genomic deletions are major founder mutations in Dutch breast cancer patients (published erratum appears in Nat Genet Dutch breast cancer patients (published
1997;17:503). Nat Genet 1997;17:341-5.

30 Puget N, Sinilnikova OM, Stoppa-Lyonnet D, Audoynaud C, Pages S, Lynch HT, Goldgar D, Lenoir GM, Mazoyer S. An Alu-mediated 6-kb duplication in the BRCA1 gene: a new founder mutation? Am ₹ Hum Genet 1999;64:300-2.

31 Purandare SM, Patel PI. Recombination hot spots and human disease. Genome Res 1997;7:773-86.

32 Swensen J, Hoffman M, Skolnick MH, Neuhausen SL. Identification of a 14 $\mathrm{kb}$ deletion involving the promoter region of BRCA1 in a breast cancer family. Hum Mol Genet 1997;6:1513-17.

33 Rudiger NS, Gregersen N, Kielland-Brandt MC. One short well conserved region of Alu-sequences is involved in human gene rearrangements and has homology with prokaryotic chi. Nucleic Acids Res 1995;23:256-60.

34 Centra M, Memeo E, d'Apolito M, Savino M, Ianzano L, Notarangelo A, Liu J, Doggett NA, Zelante L, Savoia A. Fine exon-intron structure of the Fanconi anemia group A (FAA) gene and characterization of two genomic deletions. Genomics 1998;51:463-7.

35 Levran O, Doggett NA, Auerbach AD. Identification of Alu-mediated deletions in the Fanconi anemia gene FAA. Hum Mutat 1998;12:145-52.

36 Bullock P, Champoux JJ, Botchan M. Association of crossover points with topoisomerase I cleavage sites: a model for nonhomologous recombination. Science 1985;230:954-8.

37 Schrock E, Veldman T, Padilla-Nash H, Ning Y, Spurbeck J, Jalal S, Shaffer LG, Papenhausen P, Kozma C, Phelan MC, Kjeldsen E, Schonberg SA, O'Brien P, Biesecker L, du Manoir S, Ried T. Spectral karyotyping refines cytogenetic diagnostics of constitutional chromosomal abnormalities. Hum Genet 1997;101:255-62.

38 Michalet X, Ekong R, Fougerousse F, Rousseaux S, Schurra C, Hornigold $\mathrm{N}$, van Slegtenhorst M, Wolfe J, Povey S, Beckmann JS, Bensimon A. Dynamic molecular combing: stretching the whole human genome for high- resolution studies. Science 1997;277:1518-23.

39 Yau SC, Bobrow M, Mathew CG, Abbs SJ. Accurate diagnosis of carriers of deletions and duplications in Duchenne/Becker muscular dystrophy by fluorescent dosage analysis. F Med Genet 1996;33:550-8.

40 Cargill M, Altshuler D, Ireland J, Sklar P, Ardlie K, Patil N, Lane CR, Lim EP, Kalayanaraman N, Nemesh J, Ziaugra L, Friedland L, Rolfe A, Warrington J, Lipshutz R, Daley GQ, Lander ES. Characterization of single-nucleotide polymorphisms in coding regions of human genes. Nat Genet 1999;22:231-8.

41 Eng C, Vijg J. Genetic testing: the problems and the promise. Nat Biotechnol 1997;15:422-6. 
Attitudes towards termination of pregnancy in subjects who underwent presymptomatic testing for the $B R C A 1 / B R C A 2$ gene mutation in The Netherlands

EDITOR-The identification of the BRCA1 and BRCA2 gene mutations in 1994 and 1995 respectively ${ }^{12}$ allowed detection of mutation carriers in families with autosomal dominant hereditary breast/ovarian cancer. Female mutation carriers have a risk of $56-87 \%$ of developing breast cancer and of $10-60 \%$ for ovarian cancer. ${ }^{3}$ The options are either frequent surveillance or prophylactic surgery. For male mutation carriers, cancer risks are only slightly increased. The offspring of mutation carriers have a $50 \%$ chance of inheriting the gene mutation. The possibility of prenatal genetic diagnosis for "late onset diseases", such as hereditary breast/ovarian cancer, raises complex ethical questions. ${ }^{45}$ The present study addresses the question to what extent physicians and policy makers working in genetics or oncology may expect requests for prenatal diagnosis and termination of pregnancy because of carriership for BRCA1/BRCA2.

A questionnaire assessing attitudes towards termination of pregnancy if the fetus was found to be a $B R C A 1 / B R C A 2$ female or a male mutation carrier was answered by 78 subjects (67 women and $11 \mathrm{men}$ ) who underwent presymptomatic DNA testing for hereditary breast/ovarian cancer, six months after receiving their test results. Subjects were asked to indicate to what extent they found termination of pregnancy acceptable for themselves. Subjects with and without a desire to have children were included in the study. There were 26 carriers of the BRCA1/BRCA2 mutation ( 23 females/three males, mean age 36.5 ) and 52 non-mutation carriers (44 females/eight males, mean age 38.8). The latter group served as a reference group; they cannot transmit the mutation to their offspring, but are well informed about the implications of hereditary breast/ ovarian cancer.

None of the 26 mutation carriers found termination of pregnancy in the case of a female or a male mutation carrier fetus as acceptable for themselves. A minority of the non-mutation carriers viewed termination of pregnancy as acceptable in the case of a female $(14 \%)$ or a male mutation carrier fetus $(10 \%$, table 1$)$. The differences between mutation and non-mutation carriers are significant $(p<0.05$, Pearson chi-square test, SPSS/PC, release 8.0). Five of the seven non-mutation carriers accepting termination of pregnancy thought this to be acceptable independent of the sex of the mutation carrier child. This is surprising, since the lifetime risk of developing cancer for males with a $B R C A 1 / B R C A 2$ mutation is not so high. However, the majority of the non-mutation carriers and all the mutation carriers in the present study rejected termination of pregnancy in the case of a child who (1) has

Table 1 Attitudes of BRCA1/BRCA2 mutation carriers and non-mutation carriers towards termination of pregnancy because of a fetus carrying a mutation

\begin{tabular}{lll}
\hline $\begin{array}{l}\text { If there was a pregnancy in my family, I would } \\
\text { find termination of pregnancy acceptable if the } \\
\text { child was: }\end{array}$ & $\begin{array}{l}\text { Mutation } \\
\text { carriers } \\
(n=26)\end{array}$ & $\begin{array}{l}\text { Non-mutation } \\
\text { carriers }(n=52)\end{array}$ \\
\hline A female BRCA1/BRCA2 mutation carrier & $0 \%$ & $13.5 \%$ \\
A male BRCA1/BRCA2 mutation carrier & $0 \%$ & $9.6 \%$ \\
\hline
\end{tabular}

a high risk of developing breast or ovarian cancer later in life (a girl) and/or (2) can transmit the gene to his/her offspring (boy or girl).

The stronger reluctance in mutation carriers than in non-mutation carriers towards terminating a pregnancy of a mutation carrier boy or girl may have several reasons. Firstly, mutation carriers may be more acutely aware of the burdensome emotional implications of terminating a pregnancy because of $B R C A 1 / B R C A 2$ carriership than nonmutation carriers. Secondly, they may perceive terminating the pregnancy of a mutation carrier child as incompatible with their own existence.

In subjects at risk for autosomal dominant Huntington's disease, the actual demand for prenatal diagnosis and termination of pregnancy is much lower than would be expected based on studies assessing attitudes towards these techniques. ${ }^{67}$ Prenatal diagnosis and termination of pregnancy for late onset diseases, with decades of healthy life before onset of the disorder, are considered very difficult choices for parents. In our experience of 500 families at risk for hereditary breast/ovarian cancer seen during the past five years, two requests for prenatal diagnosis were made by recently identified mutation carriers, who wanted to have children in the near future. Considering the few actual requests for prenatal diagnosis for $B R C A 1 / B R C A 2$, the emotional burden of such a decision, and the general reluctance to terminate a pregnancy of a mutation carrier child (this study), the demand for prenatal diagnosis in hereditary breast/ovarian cancer families is expected to remain low. Genetic counselling of couples considering these highly complex and burdensome options should focus on supporting parents in the decision making process. There are no general rules of wisdom or ethical desirability that could take priority over finding individual solutions and the need to support each couple.

This study is part of a larger study on psychosocial implications of the presymptomatic DNA test for HBOC, which is funded by the Dutch Cancer Society. P G FRETS ${ }^{\star}$ $\mathrm{R}$ W TRIJSBURG* E J MEIJERS-HEIJBOER† J G M KLIJN M F NIERMEIJER†

${ }^{\star}$ Department of Medical Psychology and Psychotherapy, Erasmus University Rotterdam/Netherlands Institute for Health Sciences, PO Box 1738, 3000 DR Rotterdam, The Netherlands

†Department of Clinical Genetics, University Hospital Dijkzigt/Erasmus University Rotterdam, Rotterdam, The Netherlands

$\ddagger$ Department of Medical Oncology, Daniel den Hoed Cancer Center, Rotterdam, The Netherlands

Correspondence to: Dr Lodder, L.N.Lodder@freeler.nl

1 Miki Y, Swensen J, Shattuck-Eidens D, Futreal PA, Harshman K, Tavtigian S, Liu Q, Cochran C, Bennett LM, Ding W, Bell R, Rosenthal J, Hussey C, Tran T, McClure M, Frye C, Hattier T, Phelps R, Haugen-Strano A, Tran T, McClure M, Frye C, Hattier T, Phelps R, Haugen-Strano A,
Katcher H, Yakumo K, Gholami Z, Shaffer D, Stone S, Bayer S, Wray C, Katcher H, Yakumo K, Gholami Z, Shaffer D, Stone S, Bayer S, Wray C,
Bogden R, Dayananth P, Ward J, Tonin P, Narod S, Bristow PK, Norris FH, Bogden R, Dayananth P, Ward J, Tonin P, Narod S, Bristow PK, Norris FH,
Helvering L, Morrison P, Rosteck P, Lai M, Barrett JC, Lewis C, Neuhausen S, Cannon-Albright L, Goldgar D, Wiseman R, Kamb A, Skolnick $M H$. A strong candidate for the breast and ovarian cancer susceptibility gene BRCA1. Science 1994;266:66-71.

2 Wooster R, Bignell G, Lancaster J, Swift S, Seal S, Mangion J, Collins N, Gregory S, Gumbs C, Micklem G, Barfoot R, Hamoudi R, Patel S, Rice C, Biggs P, Hashim Y, Smith A, Connor F, Arason A, Gudmundsson J, Ficenec D, Kelsell D, Ford D, Tonin P, Bishop DT, Spurr NK, Ponder BAJ, Eeles R, Peto J, Devilee P, Cornelisse C, Lynch H, Narod S, Lenoir G, Egilsson V, Barkadottir RB, Easton DF, Bentley DR, Futreal PA, Ashworth A, Stratton MR. Identification of the breast cancer susceptibility gene BRCA2. Nature 1995;378:789-92.

3 Blackwood MA, Weber BL. BRCA1 and BRCA2: from molecular genetics to clinical medicine. F Clin Oncol 1998;16:1969-77.

4 Lancaster JM, Wiseman RW, Berchuck A. An inevitable dilemma: prenatal testing for mutations in the BRCA1 breast-ovarian cancer susceptibility testing for mutations in the BRCA1
gene. Obstet Gynecol 1996;87:306-9.

5 Wagner TM, Ahner R. Prenatal testing for late-onset diseases such as mutations in the breast cancer gene 1 (BRCA1). Just a choice or a step in the wrong direction? Hum Reprod 1998;13:1125-6. 
6 Tibben A, Frets PG, van de Kamp JJ, Niermeijer MF, Vegter van der Vlis M, Roos RA, Rooymans HG, van Ommen GJ, Verhage F. Presymptomatic DNA-testing for Huntington disease: pretest attitudes and expectations of applicants and their partners in the Dutch program. Am f Med Genet 1993; 48:10-16.
7 Adam S, Wiggins S, Whyte P, Bloch M, Shokeir MHK, Soltan H, Meschino W, Summers A, Suchowersky O, Welch JP, Huggins, M, Theilmann, J, Hayden MR. Five year study of prenatal testing for Huntington's disease: demand, attitudes, and psychological assessment. F Med Genet 1993;30:

\section{Detailed mapping, mutation analysis, and intragenic polymorphism identification in candidate Noonan syndrome genes MYL2, DCN, EPS8, and RPL6}

EDITOR-Noonan syndrome (NS) is an autosomal dominant developmental disorder in which the cardinal features include short stature, typical facies with hypertelorism, ptosis, downward slanting palpebral fissures, and low set, posteriorly rotated ears. In addition, there is a notable cardiac involvement seen in these patients, principally pulmonary valve stenosis and hypertrophic obstructive cardiomyopathy. ${ }^{2}$ The frequency of NS has been estimated to be between 1:1000-1:2500 live births. ${ }^{23}$

Using linkage analysis in a large three generation pedigree, we have previously mapped a gene for NS to an interval of more than $6 \mathrm{cM}$ on $12 \mathrm{q} 24$ flanked by the markers D12S1637 and NOS1. ${ }^{45} \mathrm{~A}$ similar analysis in smaller two generation families showed genetic heterogeneity for this disorder. ${ }^{4}$ Despite the relatively high incidence of NS, there appears to be a distinct lack of large families suitable for linkage analysis, possibly resulting from an increase of infertility in males. ${ }^{6}$ However, the location of the NS gene has recently been further refined to a $5 \mathrm{cM}$ interval through the identification of additional recombinants in one additional large NS family. ${ }^{7}$ No chromosome rearrangements associated with the disease have so far been discovered. In view of this, one approach currently being used to identify the underlying gene responsible for this disorder is examination of candidate genes from within this large region of chromosome 12 . We present below the examination of four candidate genes, the precise localisation of three of which, epidermal growth factor receptor pathway substrate-8 (EPS8), decorin (DCN), and myosin light chain 2 (MYL2), had not previously been accurately determined. The fourth, ribosomal protein L6 (RPL6) was known to lie within the NS interval on $12 \mathrm{q} 24 .^{8}$

PCR was used to produce gene specific products for FISH (see below) and to produce exonic fragments for SSCP (see below). Sequence information from the cDNA clones of epidermal growth factor receptor pathway substrate-8 (EPS8) and decorin (DCN) were used to design primers for FISH. Primers used were GACAACTAACAGCATCCAGC ( $D C N-F)$, GGATTCCTACTTGCCTTGGA (DCN-R), CTTCCTTATTCTTGGTGT (EPS8-F), and CTCGAACTTGGGTCATTG (EPS8-R). The primers used for SSCP analysis of the MYL2 and RPL6 genes, and for the FISH of MYL2 (exon 4 product) are shown in table 1 . Thermocycling parameters were $96^{\circ} \mathrm{C}$ for five minutes, 35 cycles of $96^{\circ} \mathrm{C}$ for 30 seconds, $55^{\circ} \mathrm{C}(D C N)$ or $50^{\circ} \mathrm{C}$ (EPS8) for 30 seconds, and $72^{\circ} \mathrm{C}$ for 30 seconds, using $1.5 \mathrm{mmol} / 1$ $\mathrm{MgCl}_{2}$. The primers for DCN, EPS8, and MYL2 were produced from database sequences. Those for RPL6 were derived from sequences determined by one of the authors.

The subchromosomal localisation of each gene was determined by hybridisation of fluorescently labelled PCR products to metaphase chromosome spreads. ${ }^{9}$ PCR products for DCN, EPS8, and MYL2 (exon 4 product) were labelled using the PCR Digoxigenin Probe Synthesis nick translation kit (Boehringer Mannheim). Conditions for hybridisation and immunofluorescent detection were performed according to the manufacturer's instructions.

Primers for SSCP analysis of genomic DNA were designed from intronic sequences such that the entire exon and flanking splice sites could be analysed (table 1). PCR conditions were optimised for each primer set and are available upon request. Amplified fragments were analysed for SSCP on a $30 \times 40 \mathrm{~cm}$ gel containing $5 \%$ acrylamide, $0.25 \%$ bisacrylamide, with and without $10 \%$ glycerol in TBE $(100 \mathrm{mmol} / 1$ Tris, $100 \mathrm{mmol} / 1$ boric acid, $2 \mathrm{mmol} / \mathrm{l}$ $\mathrm{Na}_{2}$ EDTA, $\mathrm{pH}$ 8.3). Electrophoresis was performed at 30 $\mathrm{W}$ and $4^{\circ} \mathrm{C}$.

EPS8 is highly conserved between species, ${ }^{10}$ is widely expressed during mouse development, ${ }^{11}$ and had previously been assigned to $12 \mathrm{q} 24 .{ }^{10}$ However, our FISH analysis localised the gene to chromosome 12p13.2 (fig 1). To confirm this localisation, the EPS 8 cDNA was used to screen a chromosome 12 specific cosmid library (Lawrence Livermore National Laboratory, kindly provided by Dr Sue Chamberlain). The positive clones obtained also hybridised to chromosome $12 \mathrm{p} 13$, confirming the localisation and exclusion of this gene (fig 1).

Through its ability to bind extracellular matrix constituents and growth factors, $D C N$ is thought to play an impor-

Table 1 Oligonucleotide sequences flanking each of the exons of the MYL2 and RPL6 genes

\begin{tabular}{lll}
\hline & Forward 5'-3' & Reverse 5'-3' \\
\hline MYL2 & & \\
Exon 1 & CTCACCTATGACTGCCAAAAG & CCCTCGCTTGTAGTGGCTTC \\
Exon 2 & CCCAGAGTAGGGGCCTGACCTAG & CCATCCAGGCGGATGATTCAATAG \\
Exon 3 & CCAGGCTGAGCTGCCAATCAC & CATGCAGGGCTAGAGAGGGGT \\
Exon 4 & CCCTGAGTGTGTTTCCTACCC & TTCTGCCAGCCCCCCGAAGAA \\
Exon 5 & CCCAGCCACCCCCAGTACATGT & CCCGAACGCTGCAGAGAAAGA \\
Exon 6 & GACACCAACACCTGCTTTCCTTTC & GGAGAACCAGGAGCTGGGTTAGAGG \\
Exon 7 & CTTAGCACGTGTTGCTGGCTCA & CACTCTGCAAAGACGAGCCCA \\
RPL6 & & \\
Exon 1 & CCGGCCTAGGATTTACTA & CTCAGTTAGCCTTGGACATG \\
Exon 2 & TTGTTAGAGAGATGACTGGTG & CAATTAAGGTTAAGACATAATGG \\
Exon 3 & CTTAATTGGCATTCTCTTACTG & TTCAAGCATAAACAGGAAATCC \\
Exon 4 & GCTTCTAGTAATCTGAATGGC & GCAGCTGCAGTGAAGCGC \\
Exon 5 & GATGCCTGTGATTTTATGAATTC & AAGTTTCACAGAACATCAC \\
Exon 7 & CACCTAAATTGCAGGATGATG & CAGTGCTAACACAGGAGATG \\
\hline
\end{tabular}




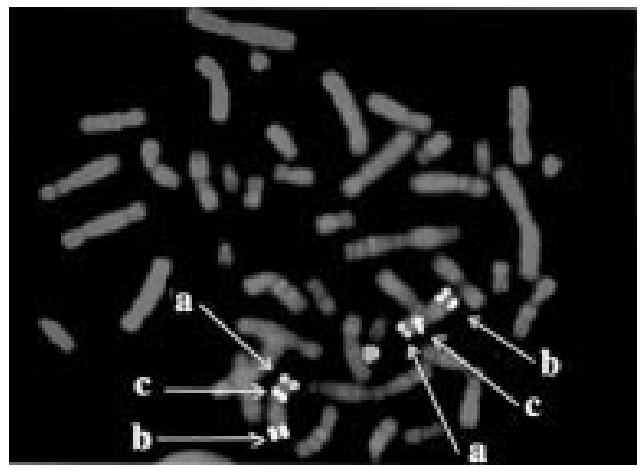

Figure 1 FISH using cosmid c62A3 that contains a fragment of the EPS8 gene. The cosmid (a) hybridised to the distal part of 12p. YACs $887 b 9$ and $955 d 8$ (b) flank the NS critical region at $12 q 24$. A biotinylated $12 a$ satellite probe (ONCOR) was used as a marker for chromosome 12 (c).

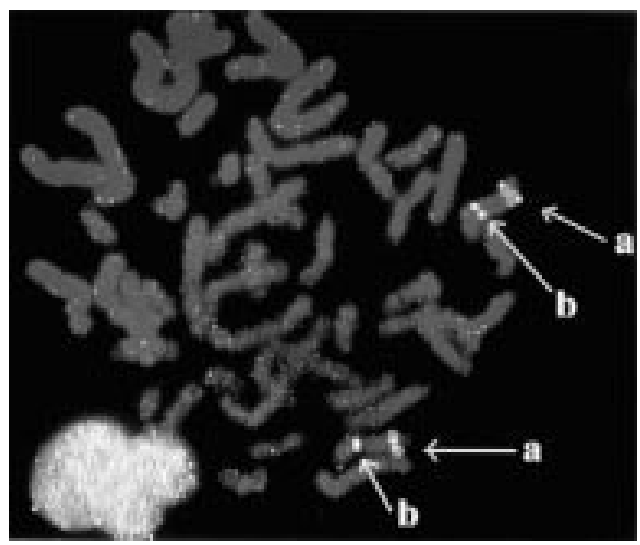

Figure 2 FISH using cosmid $91 F 7$ that contains part of the MYL2 gene. The cosmid hybridised in the NS critical region between the YACs $887 b 9$ and $955 d 8$ (shown together as a). A biotinylated 12 a satellite probe (ONCOR) was used as a marker for chromosome 12 (b).

tant role in the remodelling and maintenance of extracellular matrices. ${ }^{12}{ }^{13}$ Two previous studies, both using radiolabelled in situ hybridisation, suggested different localisations for the $D C N$ gene on chromosome 12 at bands $12 \mathrm{q} 21-\mathrm{q} 22$ and $12 \mathrm{q} 23 .{ }^{14}{ }^{15}$ In view of its proposed function, $D C N$ would be an excellent candidate for NS if it mapped within the interval. FISH clearly showed that the $D C N$ gene maps at $12 \mathrm{q} 13.2 \mathrm{q}$ proximal to both of the previous locations, and once again can be excluded as a candidate for NS.

While the genes described above were shown to be located outside the NS locus, this was not the case for the MYL2 gene. MYL2 has previously been assigned to chromosome $12 \mathrm{q} 23-\mathrm{q} 24.3$ by in situ hybridisation. ${ }^{16}$ Although the precise function of the protein is not understood, MYL2 is known to be critical for the correct regulation of myosin ATPase activity in smooth muscle. ${ }^{17}$ The nonmuscle myosin II-B is known to be required for normal development of the mouse heart ${ }^{18}$ and an increase in ventricular MYL2 has been observed during myocardial hypertrophy in patients with valvular stenosis. In addition, missense mutations within the MYL2 gene have been identified in patients with a rare variant of cardiac hypertrophy, ${ }^{17}$ an intriguing observation in view of the cardiac anomalies associated with NS. As a result of its position and putative function, MYL2 was regarded as a strong candidate gene for NS.

Using a labelled MYL2 gene fragment in conjunction with genomic clones that flank the NS critical interval, we were able to show that the MYL2 gene overlaps the assign- ment of the NS gene at 12q24 (fig 2). Sequence information from the MYL2 gene was used to design primers, which were used in SSCP analysis in 22 familial $^{4}$ and 44 sporadic NS patients. Primers were designed which flanked each of the seven MYL2 exons including splice sites (table 1). Three band shifts were detected in these regions (data not shown). However, the same shifts were also seen with a high frequency in normal controls, or the corresponding change in the nucleotide sequence did not lead to an amino acid substitution, indicating that these changes represent normal polymorphisms. Sequencing showed one substitution at codon 44 (ATT to ATC) which does not result in an amino acid change, while the others were the result of variations in a GT repeat immediately 3' to exon 4 . The absence of any pathogenic mutations in the coding regions of $M Y L 2$ in any NS patients makes it unlikely that this is the causative gene.

In Drosophila, mutations in genes for the ribosomal proteins have been shown to cause the minute phenotype, which includes small body size, diminished fertility, and specific somatic abnormalities. ${ }^{19-21}$ Furthermore, the ribosomal protein genes RPS $4 X$ and RPS4Y are discussed as "candidate" genes for Turner syndrome. ${ }^{22-24}$ Turner syndrome and NS have short stature and webbing of the neck as common symptoms. Heart malformations, although of a different type, are also associated with both disorders. The human RPL6 gene is located in the NS critical interval, ${ }^{82}$ suggesting this gene as a candidate.

To check for possible mutations, the six coding exons of the RPL6 gene as well as the preceding exon containing the 5'UTR were screened by SSCP analysis in the same subset of NS patients as used for the MYL2 gene. The primers are shown in table 1 . In exon 4 , a point mutation was found in two unrelated affected subjects from small families with only two parents and two sibs. This mutation is predicted to cause the substitution of lysine, residue 139 , for an asparagine (Lys139Asn). While the substitution cosegregates with NS in one family, it does not in the second, in which NS does not cosegregate with the critical region on chromosome 12 . No mutations were found in the large family with NS linked to 12q24, and the Lys139Asn substitution was also seen in one out of 150 unaffected controls, showing this A to C transversion to be a rare polymorphism. As for MYL2, the analysis suggests that a role for RPL6 in NS is unlikely. Mutations influencing the expression of these genes cannot yet be excluded as being causative for NS.

In summary, as part of a positional candidate cloning strategy to identify a gene for NS, we have examined a number of potentially interesting candidate genes on chromosome 12. Two were excluded by FISH, while two others located within the NS critical interval showed no causative mutations. In the absence of additional recombination events in NS families which can be unequivocally linked to chromosome 12, a screening strategy geared towards the identification of any chromosomal rearrangements within the NS critical interval is currently being used. In conjunction with this approach, the construction of a genomic contig encompassing the entire NS critical interval, and its sequencing, is also in progress.

The first three authors contributed equally to this work. We would like to thank the Birth Defects Foundation and the British Heart Foundation (grant PG/95077) for their support, and the Dutch Heart Foundation for funding HK and MvR.

A ION ${ }^{\star} ¥$

A H CROSBY $¥$

H KREMER $¥ ¥$

N KENMOCHI

M VAN REEN† $¥$

C FENSKE $¥$

I VAN DER BURGT $¥$ H G BRUNNER+ $¥$ K MONTGOMERY@ $¥$ 
R S KUCHERLAPATI\$ $¥$ $M$ A PATTON $¥ ¥$ D C PAGE

E MARIMAN† $¥$ S JEFFERY $¥$

${ }^{\star}$ Medical Genetics Unit, St George's Medical School, Cranmer Terrace, Tooting, London SW17 ORE, UK

†Department of Human Genetics, University Hospital Nijmegen, Geert Grooteplein 10, Nijmegen, The Netherlands

$\ddagger$ Department of Biochemistry, School of Medicine, University of the Ryukyus, Nishihara, Okinawa, Fapan

\Molecular Genetics Department, Albert Einstein College of Medicine, Bronx, New York, USA

-Howard Hughes Medical Institute, Whitehead Institute and Department of Biology, Massachusetts Institute of Technology, Cambridge, Massachusetts, USA

Correspondence to: Dr Jeffery, sggt100@sghms.ac.uk

$¥$ Members of the Noonan Syndrome Collaborative Group.

1 Mendez HMM, Opitz JM. Noonan syndrome; a review. Am $\mathcal{f}$ Med Genet 1985;21:493-506

2 Ion A, Patton MA. Noonan syndrome. Curr Paediatr 1998;8:113-16.

Nora JJ, Nora AH, Sinha AK, Spangler RD, Lubs HA. The Ullrich Noonan syndrome (Turner phenotype). Am $\mathcal{F}$ Dis Child 1974;127:48-55.

4 Jamieson CR, van der Burgt I, Brady AF, van Reen M, Elsawi M, Hol F, Jeffery S, Patton MA, Mariman E. Mapping a gene for Noonan syndrome to the long arm of chromosome 12. Nat Genet 1994;8:357-60.

5 Brady AF, Jamieson CR, van der Burgt I, Crosby A, van Reen M, Kremer H, Mariman E, Patton MA, Jeffery S. Further delineation of the critical region for Noonan syndrome on the long arm of chromosome 12. Eur f Hum Genet 1997;5:336-7.

6 Elsawi MM, Pryor JP, Klufio G, Barnes C, Patton MA. Genital tract function in men with Noonan syndrome. $\mathcal{F}$ Med Genet 1994;31:468-70.

7 Legius E, Schollen E, Matthijs G, Fryns JP. Fine mapping of Noonan/cardiofacio cutaneous syndrome in a large family. Eur f Hum Genet 1998;6:32-7.

8 Kenmochi N, Kawaguchi T, Rozen S, Davis E, Goodman N, Hudson TJ, Kenmochi N, Kawaguchi T, Rozen S, Davis E, Goodman N, Hudson TJ,
Tanaka T, Page DC. A map of 75 human ribosomal protein genes. Genome Tanaka T, Page DC.

9 Ion A, Telvi L, Nunes M, Rethore MO, Chaussain JL, Fellous M, McElreavey K. Failure of testicular development associated with a rearrangement of 9p24.1 proximal to the SNF2 gene. Hum Genet 1998;102:151-6.

10 Wong WT, Carlomagno F, Druck T, Barletta C, Croce CM, Huebner K, Kraus MH, DiFiore DP. Evolutionary conservation of the EPS 8 gene and its mapping to chromosome 12q23-24. Oncogene 1994;9:3057-61.
11 Avantaggiato V, Torino A, Wong WT, Di Fiore PP, Simeone A. Expression of the receptor tyrosine kinase substrate genes eps 8 and eps 15 during mouse development. Oncogene 1995;11:1191-8.

12 Ehnis T, Dieterich W, Bauer M, Kresse H, Schuppan D. Localisation of a binding site for the proteoglycan decorin on collagen XIV (undulin). $f$ Biol Chem 1997;272:20414-19.

13 Thieszen SL, Rosenquist TH. Expression of collagens and decorin during aortic arch artery development: implications for matrix pattern formation. Matrix Biol 1995;14:573-82.

14 Pulkinen L, Alitalo T, Krusius T, Peltonen L. Expression of decorin in human tissues and cell lines and defined chromosomal assignment of the gene locus (DCN). Cytogenet Cell Genet 1992;60:107-11.

15 Danielson KG, Fazzio A, Cohen I, Cannizzaro LA, Eichstetter I, Iozzo RV. The human decorin gene: intron-exon organisation, discovery of two alternatively spliced exons in the $5^{\prime}$ untranslated region, and mapping of the gene to chromosome 12q23. Genomics 1993;15:146-60.

16 Macera MJ, Szabo P, Wadgaonkar MA, Siddiqui MAQ, Verma RS. Localisation of the gene coding for ventricular myosin regulatory light chain (MYL2) to human chromosome 12q23-q24. Genomics 1992;13:82931.

17 Poetter K, Jiang H, Hassanzadeh S, Master SR, Chang A, Dalakas MC, Rayment I, Sellers JR, Fananapazir L, Epstein ND. Mutations in either the essential or regulatory light chains of myosin are associated with a rare myopathy in human heart and skeletal muscle. Nat Genet 1996;13:63-9.

18 Tullio AN, Accili D, Ferrans VJ, Yu ZX, Takeda K, Grinberg A, Westphal H, Preston YA, Adelstein RS. Nonmuscle myosin II-B is required for normal development of the mouse heart. Proc Natl Acad Sci USA 1997;94:1240712 .

19 Lindsley DL, Grell EH. Genetic variations in Drosophila melanogaster. Washington: Carnegie Institute Publications, 1968:627.

20 Kongsuwan K, Yu Q, Vincent A, Frisardi MC, Rosbash M, Lengyel JA, Merriam J. A Drosophila minute gene encodes a ribosomal protein. Nature 1985;317:555-8.

21 Saebøe-Larssen S, Lambertsson A. A novel Drosophila Minute locus encodes ribosomal protein S13. Genetics 1996;143:877-85.

22 Fisher EMC, Beer-Romero P, Brown LG, Ridley A, McNeil JA, Lawrence JB, Willard HF. Bieber FR, Page DC. Homologous ribosomal protein genes on the human $\mathrm{X}$ and $\mathrm{Y}$ chromosome: escape from $\mathrm{X}$ inactivation and possible implications for Turner syndrome. Cell 1990;63:1205-18.

23 Watanabe M, Zinn AR, Page DC, Nishimoto T. Functional equivalence of human X- and Y-encoded isoforms of ribosomal protein S4 consistent with a role in Turner syndrome. Nat Genet 1993;4:268-71.

24 Zinn AR, Alagappan RK, Brown LG, Wool I, Page DC. Structure and function of ribosomal protein $\mathrm{S} 4$ genes on the human and mouse sex chromosomes. Mol Cell Biol 1994;14:2485-92.

25 Kucherlapati R, Marynen P, Turc-Carel C. Report of the fourth international workshop on human chromosome 12 mapping, 1997. Cytogenet Cell Genet 1997;78:81-95.

\section{Hall-Riggs syndrome: a possible second affected family?}

EDITOR-Definition of the clinical and genetic features of multiple congenital anomalies/mental retardation syndromes is a difficult task that requires identification of a specific phenotype in multiple patients in the general population and within families.

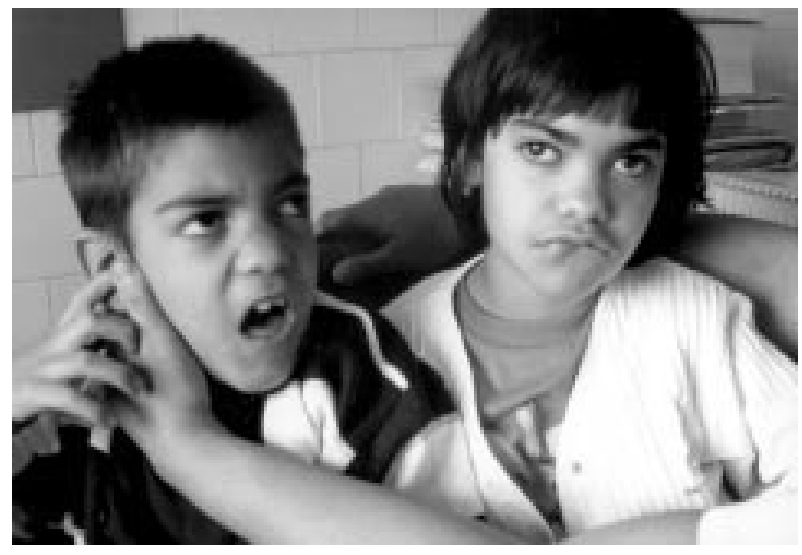

Figure 1 Facial dysmorphism of the two probands, case 1 on the right, case 2 on the left.
F Med Genet 2000;37:886-889

We report two sibs possibly affected by a rare MCA/MR syndrome, first observed by Hall and Riggs ${ }^{1}$ in 1975 . No other cases have been published since then. ${ }^{2}$

Case 1 is an $11 \frac{1 / 2}{2}$ year old female, the first born to healthy, non-consanguineous parents. Her younger male sib is case 2 of this report. She was the term product of a pregnancy complicated by threatened abortion during the first months and by intrauterine growth retardation. Birth weight was $2400 \mathrm{~g}$, length $46 \mathrm{~cm}$, and OFC $31 \mathrm{~cm}$ (all below the 3 rd centile). Apgar scores were 7 and 9 .

She has had feeding problems, failure to thrive, and severe developmental retardation. She walked unassisted at 6 years and she never achieved any language. Metabolic analysis, including amino acidaemia, amino aciduria, MPS screening, and lysosomal and peroxisomal enzymes has been negative.

Sialotransferrin, cholesterol, and 7-dehydrocholesterol were within normal limits. The EEG showed moderate multifocal irritative anomalies, without evidence of clinical seizures. MRI of the brain showed the presence of a large cyst in the septum pellucidum and a cavum vergae. The high resolution karyotype was normal, 46,XX.

Physical examination at $11^{1 / 2}$ years showed height 120 $\mathrm{cm}$, weight $23 \mathrm{~kg}$, and head circumference $47 \mathrm{~cm}$ (all $<<3$ rd centile). She has severe microcephaly, hypertelorism, a flat nasal bridge, a large nose with a large nasal tip, and anteverted nostrils. The mouth is wide and carp shaped. Both the upper and lower lips are thick and everted, giving a coarse appearance to the lower part of the face (fig 1). The permanent teeth have not yet erupted and 


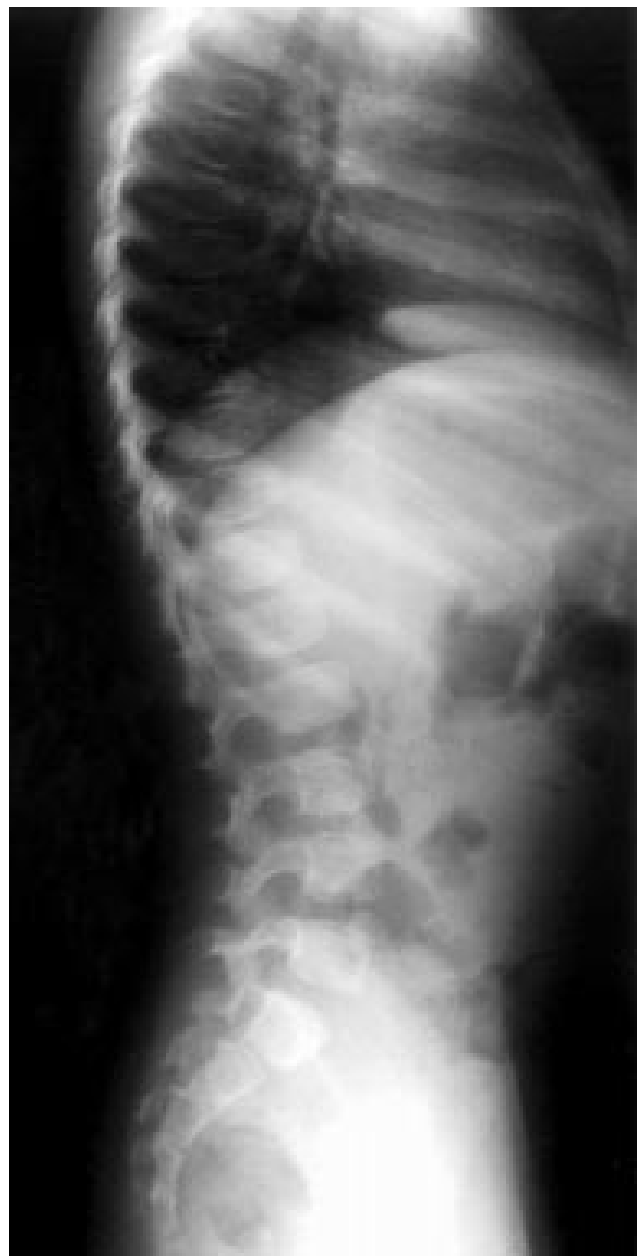

Figure 2 Lateral spine $x$ rays of case 1: irregular end plate of vertebrae and platyspondyly.

the deciduous teeth are small and have enamel hypoplasia. The hair is coarse and thick but microscopic examination does not show significant changes. Sweating is normal.

She has scoliosis and dorsal kyphosis. Spinal $x$ rays show irregular end plates of the vertebrae and platyspondyly (fig 2). On lower limb $x$ ray, there are signs of mild metaphyseal dysplasia as well as epiphyseal hypoplasia and diffuse osteoporosis (fig 3). The femoral necks and epiphyses are small and dysplastic (fig 4). Hand $x$ rays show mild brachydactyly, most evident in the distal phalanx of the thumbs, and a retarded bone age.

Case 2 is the 9 year old male sib of case 1 . He was born at term after an uneventful pregnancy. Amniocentesis showed a normal male karyotype, 46,XY. Birth weight was $2850 \mathrm{~g}$, length $47 \mathrm{~cm}$, and OFC $33 \mathrm{~cm}$. The child showed severe growth and developmental retardation.

He does not walk yet and does not have any language. His behaviour is characterised by continuous psychomotor agitation and instability. He has had three episodes of generalised seizures at 4 years of age and EEG showed important multifocal anomalies. On barbiturate therapy he has been free of seizures since then. MRI of the brain showed a large cyst in the septum pellucidum and cavum vergae (fig 5).

On physical examination, he is small (height $112 \mathrm{~cm}$, weight $12 \mathrm{~kg}$, both $<<3$ rd centile). He has microcephaly (OFC $46 \mathrm{~cm},<<3$ rd centile) and facial dysmorphism identical to that of his sister (fig 1). Mild brachydactyly with stub thumbs was observed.

Skeletal $x$ ray showed changes of a mild spondylometaphyseal dysplasia with epiphyseal involvement (figs 6 and

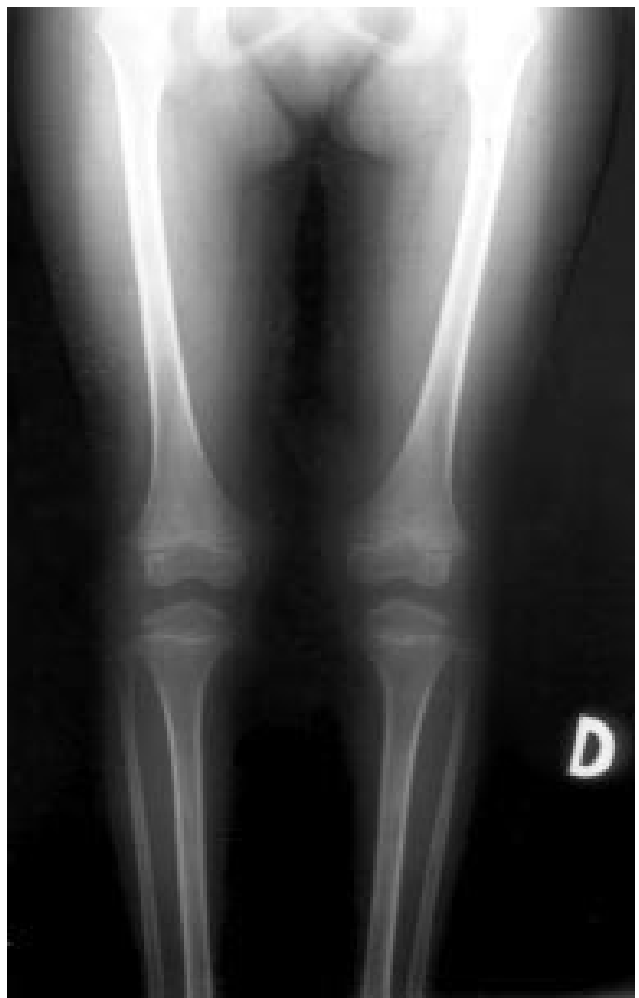

Figure 3 Lower limb $x$ rays of case 1 showing irregular metaphyses and epiphyses.

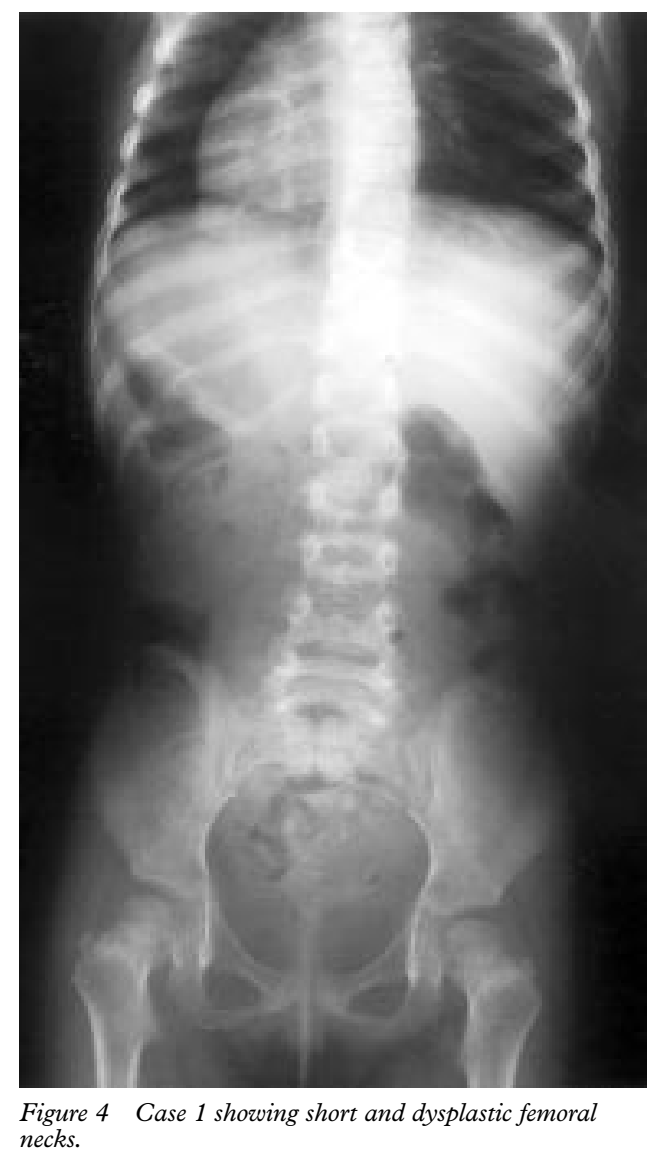

fig $7^{7}$ ). Abdominal echography was unremarkable and an audiogram was normal. Metabolic analyses were negative and lysosomal enzymes in leucocytes and cultured skin 


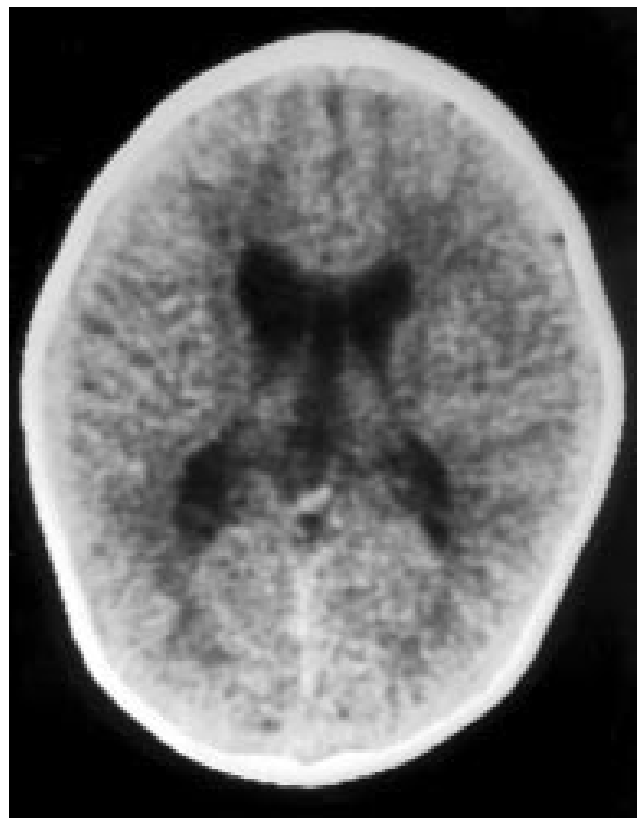

Figure 5 Case 2: MRI of the brain showing a large cyst in the septum pellucidum.

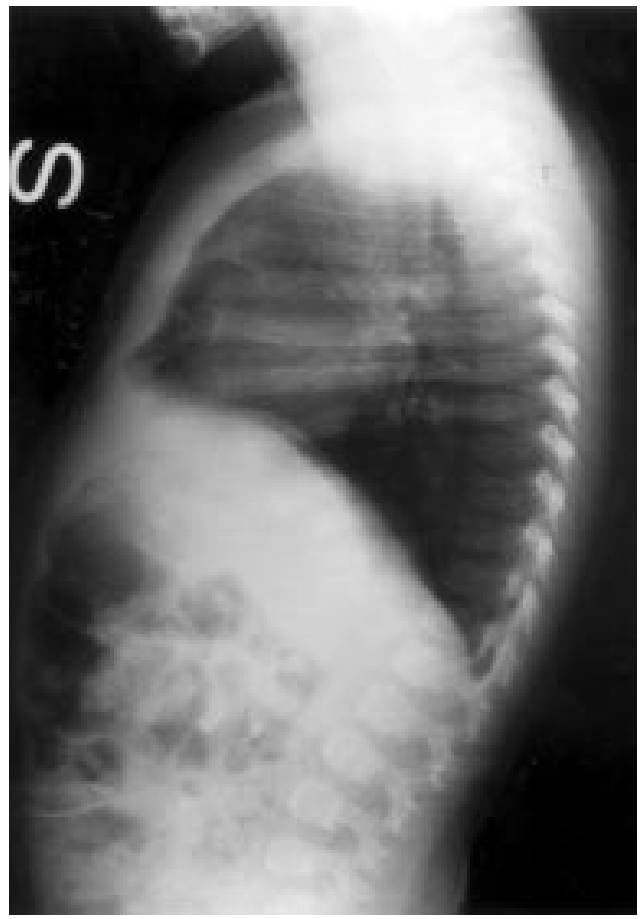

Figure 6 Case 2 showing oval shaped vertebral bodies.

fibroblasts were normal. The high resolution blood karyotype was normal.

The two sibs we have described have a malformation syndrome similar to that observed by Hall and Riggs ${ }^{1}$ in six out of 14 sibs born to consanguineous parents. Common clinical findings are severe developmental retardation, short stature, microcephaly, and dysmorphic facial features. All the affected patients have mild and nonspecific spondyloepiphyseal and metaphyseal changes (table 1).

We add a few new features to the spectrum of this rare, autosomal recessive condition. These include EEG abnormalities, midline brain defects such as large cysts of the septum pellucidum and enlarged cavum vergae, and abnormal dentition.

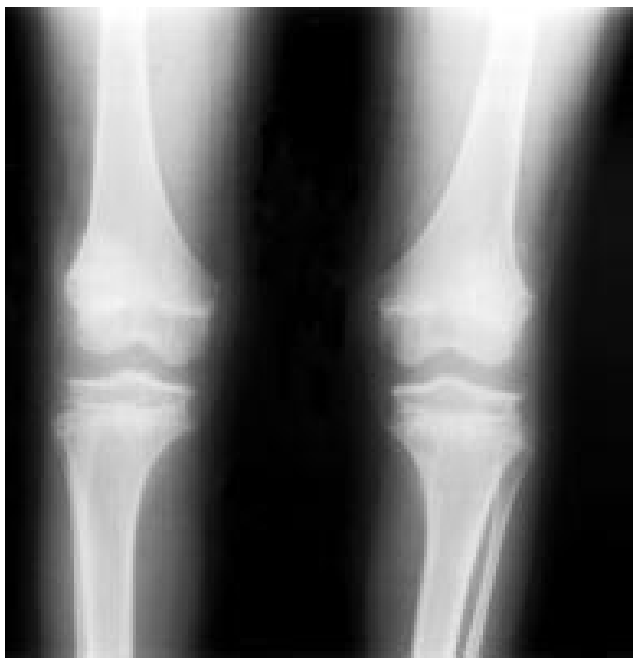

Figure $7 \quad X$ rays of the knees of patient 2 illustrating metaphyseal and epiphyseal changes.

Hall and Riggs ${ }^{1}$ suggested a metabolic basis for the condition they observed in their patients. Two of the affected sibs had an unusual pattern of biochemical abnormalities in their cultured fibroblasts consisting of decreased $\beta$-glucoronidase and increased $\mathrm{N}$-acetyl- $\beta$ glucosaminidase activities. However, these preliminary studies have not been confirmed or detailed in further reports. An extensive work up for metabolic disorders has been carried out in our cases but no inborn error of metabolism was discovered.

The skeletal changes present in our cases as well as those described by Hall and Riggs ${ }^{1}$ involve the spine, the metaphyses, and the epiphyses but are milder and different from those observed in the known forms of spondylometaphyseal and spondyloepimetaphyseal dysplasias. ${ }^{34}$

The facial dysmorphism and the skeletal changes are different from those observed by Hunter ${ }^{5}$ in his patients with spondylometaphyseal dysplasia. The dental anomalies present in our probands consist of permanence of the deciduous dentition; the panorex, however, shows the presence of all the germs of the permanent teeth. Hypodontia and conical incisors were the changes observed by Rao et $a l^{6}$ in two sibs with a unique form of spondyloepimetaphyseal dysplasia.

Identification and description of further cases are needed in order to elucidate the aetiology and pathogenesis of the rare autosomal recessive Hall-Riggs syndrome.

Table 1 Clinical features of the Hall-Riggs patients compared to those of our cases

\begin{tabular}{lll}
\hline & Hall-Riggs cases & Our cases \\
\hline Anamnestic features & & \\
Feeding problems/vomiting & $3 / 6$ & $2 / 2$ \\
Poor growth & $6 / 6$ & $2 / 2$ \\
Mental retardation & $6 / 6$ & $2 / 2$ \\
Absent speech & $6 / 6$ & $2 / 2$ \\
Major clinical features & & \\
Microcephaly & $6 / 6$ & $2 / 2$ \\
Epicanthic folds & $5 / 6$ & $2 / 2$ \\
Flat nasal bridge & $6 / 6$ & $2 / 2$ \\
Anteverted nares & $6 / 6$ & $2 / 2$ \\
Full lips & $6 / 6$ & $2 / 2$ \\
Additional findings & & \\
Seizures & $3 / 6$ & $2 / 2$ \\
Abnormal MRI & $?$ & $1 / 2$ \\
Abnormal dentition & $?$ & \\
Major radiological features & $4 / 6$ & $2 / 2$ \\
Delayed bone age & $4 / 6$ & $2 / 2$ \\
Epiphyseal defect & $4 / 6$ & $2 / 2$ \\
Metaphyseal defect & $2 / 6$ & $-2 / 2$ \\
Platyspondyly & $2 / 6$ & \\
Abnormal vertebrae & $1 / 6$ & \\
Brachydactyly &
\end{tabular}




\begin{abstract}
MARGHERITA SILENGO* ROBERTO RIGARDETTO† ^Dipartimento di Scienze Pediatriche e dell'Adolescenza, Universita' di Torino, Piazza Polonia 94, 10126 Torino, Italy †Cattedra di Neuropsichiatria Infantile, Universita' di Torino, Italy Correspondence to: Dr Silengo, silengo@pediatria.unito.it

1 Hall BD, Riggs FD. A new familial metabolic disorder with progressive osseous changes, microcephaly, coarse facies, flat nasal bridge and severe mental retardation. Birth Defects 1975;11:79-90.
\end{abstract}

2 Winter RM, Baraitser M. The London Dysmorphology Database and London Neurogenetics Database. 5th ed. Oxford: Oxford University Press, 1998

3 Taybi H, Lachman RS. Radiology of syndromes, metabolic disorders, and skeletal dysplasias. 4th ed. New York: Mosby-Year Book Inc, 1996:928-37.

4 Taybi H, Lachman RS. Radiology of syndromes, metabolic disorders and skeletal dysplasias. 4th ed. New York: Mosby-Year Book Inc, 1996:916-23.

5 Hunter AGH. Spondylometaphyseal dysplasia with characteristic facial appearance. Clin Dysmorphol 1996;5:329-34

6 Rao V, Morton RE, Young ID. Spondyloepimetaphyseal dysplasia and abnormal dentition: a new autosomal recessive syndrome. Clin Dysmorphol 1997;6:3-12.
EDITOR-Since the initial case of partial trisomy $6 \mathrm{q}$ was reported by de Grouchy et al, ${ }^{12}$ at least 23 additional cases have been published. The majority of these cases represent the abnormal segregation of a balanced parental chromosome translocation. While trisomy $6 \mathrm{q}$ patients do have some common characteristics, the inconsistent phenotypic features are usually attributed to an accompanying area of monosomy. Most often the deleted area is the terminal band of the recipient chromosome, ${ }^{3-13}$ although longer deletions have also been reported. ${ }^{14-16}$ Only deletion of the short arm of acrocentric chromosomes are without clinical effect, as these are the nucleolar organiser regions (NOR) containing the ribosomal genes which are present in multiple copies within the genome. Robertsonian translocation carriers, who lack two NORs, are phenotypically normal. Hence, trisomy 6q patients who lack one $\mathrm{NOR}^{2}{ }^{17-20}$ can be regarded as cases of "pure" trisomy 6q, together with cases of insertion $^{2122}$ and duplication ${ }^{23-25}$ of $6 \mathrm{q}$ material.

We report a pair of sibs who carry $\operatorname{der}(7) \operatorname{ins}(7 ; 6)(\mathrm{q} 21.11 ; \mathrm{q} 22.1 \mathrm{q} 23.3)$ mat, as confirmed by fluorescence in situ hybridisation (FISH). Their pheno-

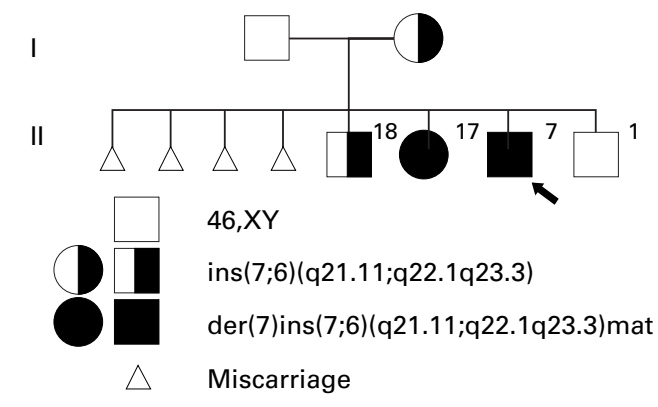

Figure 1 Family pedigree.

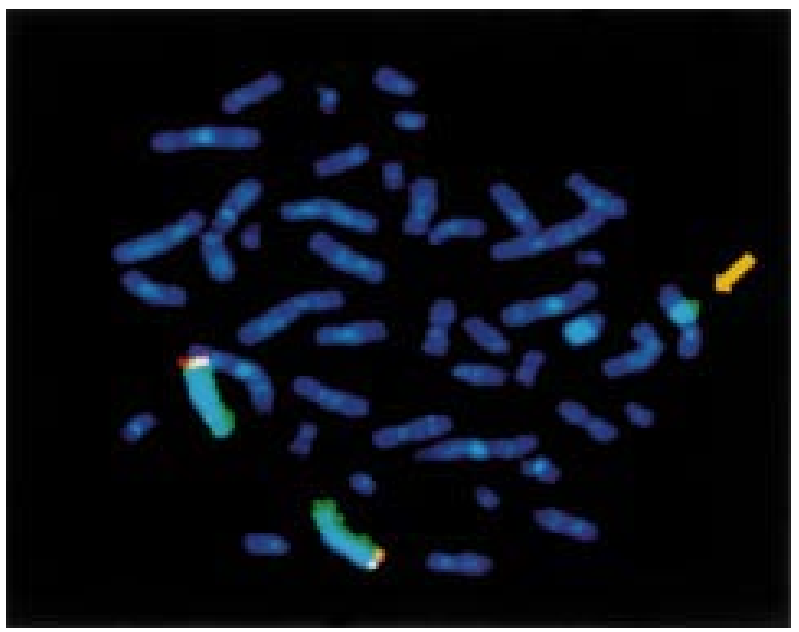

Figure 3 FISH result on proband using chromosome 6 paint (green) to indicate area of trisomy (arrowed) and red 6qter specific probe (yellow when overlapped) to indicate interstitial nature of insertion. Blue DAPI was used as counterstain.

types are compared with other cases of "pure" partial trisomy 6q.

Case 1, the proband (II.3, fig 1) is an ethnic Chinese male. He was born at term, weighing $3345 \mathrm{~g}$, to a 32 year old, gravida 7, para 2 female and a 38 year old male. He was referred aged 7 years because of his dysmorphic features and because he was failing in school. The proband's mother had had four spontaneous first trimester miscarriages before the birth of her four children. There was no known consanguinity or previous history of congenital abnormality in the family, neither was there any history of recurrent spontaneous miscarriages in the parent's sibs.

Physical examination showed central obesity with weight $(30 \mathrm{~kg})$ on the 97 th centile. Height $(124.2 \mathrm{~cm})$ was between the 90 th and 97 th centile but the head circumference $(52 \mathrm{~cm})$ was on the 50 th centile. Additional craniofacial dysmorphism consisted of brachycephaly, a flat facial profile, bushy, pointed eyebrows, mild hypertelorism, downward slanting palpebral fissures, a flat nasal bridge

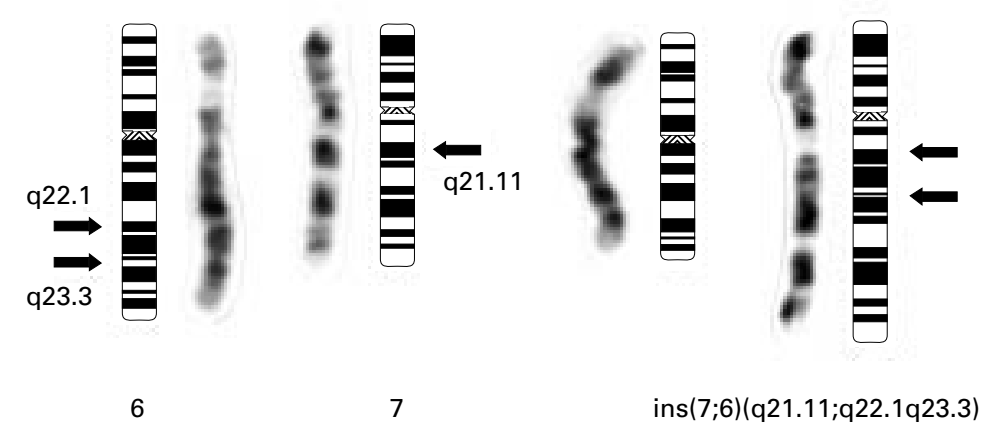

Figure $2 G$ banded chromosomes 6 and 7 of the mother with rearranged ideogram. Arrows indicate breakpoints. 

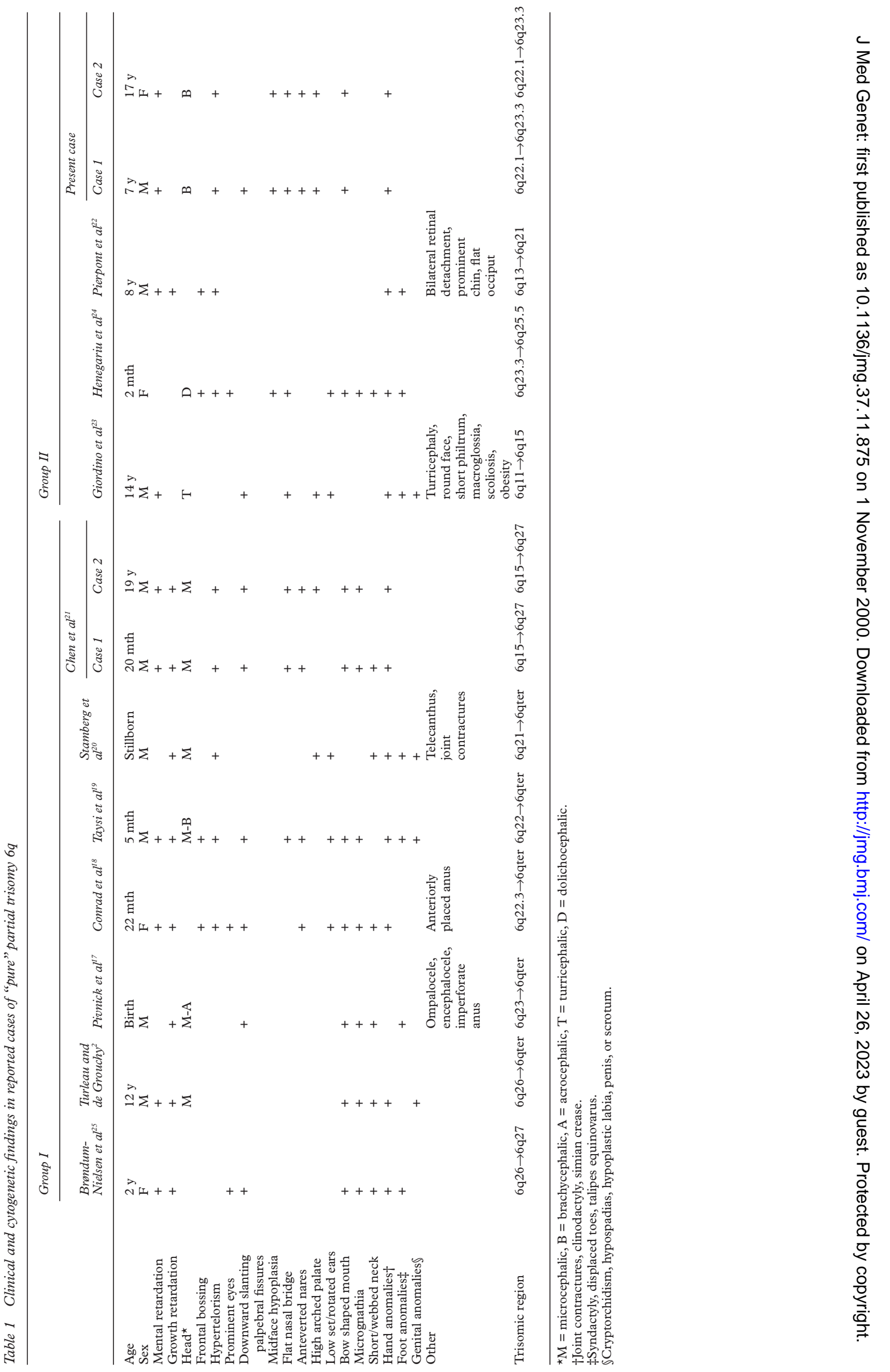


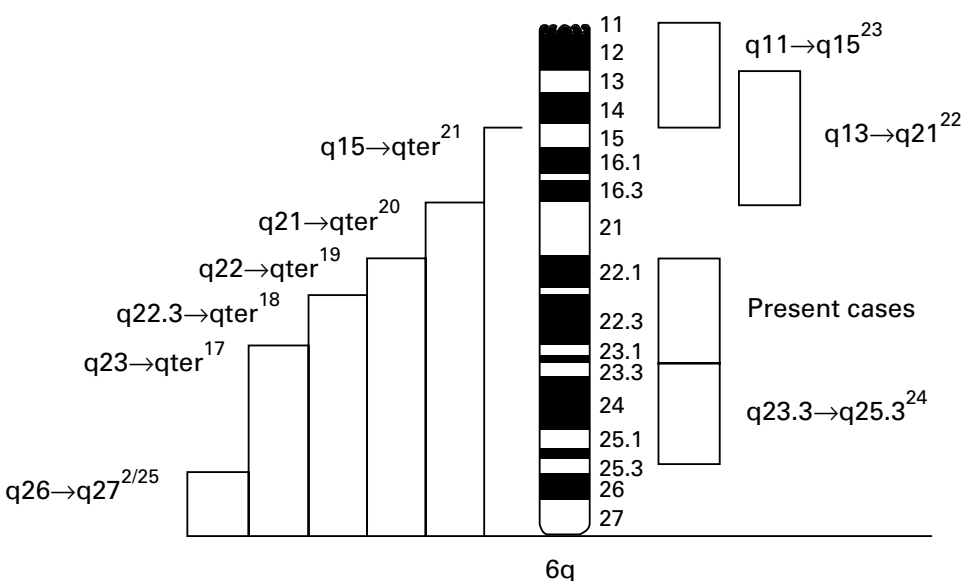

with anteverted nares, severe midfacial hypoplasia, and a bow shaped mouth with thick lips. Bilateral clinodactyly was also present. He had noisy breathing and a tendency to mouth breathe. The mother noted that he snored loudly but there were no complaints of daytime somnolence. He had been slow in attaining developmental milestones and was found to be educationally subnormal with an IQ of 50 \pm 8. A two dimensional echocardiogram, performed because of the presence of a systolic murmur, was normal. Permission to publish clinical photographs was refused.

Case 1 was evaluated for obstructive sleep apnoea (OSA) using standard polysomnography. This showed no significant obstructive apnoea. Sleep efficiency was satisfactory. There was no paradoxical inward rib cage movement during inspiration, desaturations, or bradycardia documented.

Case 2 (II.2, fig 1) is the older sister of case 1 . She was also born at term by normal delivery and weighed $3175 \mathrm{~g}$. She was seen at 17 years of age. Her height $(155.3 \mathrm{~cm})$ was between the 25 th and 50 th centile and her weight $(40.8 \mathrm{~kg})$ was between the $3 \mathrm{rd}$ and 10 th centile. She had brachycephaly, a flat facial profile, bushy, pointed eyebrows, mild hypertelorism, a flat nasal bridge with anteverted nares, midfacial hypoplasia, a bow shaped mouth, and bilateral clinodactyly. Her craniofacial features were similar to, but milder than, those of her brother. In comparison to him, she did not have downward slanting palpebral fissures or obesity and had thin lips with a long philtrum. Her secondary sexual development was found to be normal. She did not consent to formal IQ testing but was noted to have been slow in attaining developmental milestones and had left school without academic credits. She did not consent to be photographed.

Peripheral blood lymphocytes were cultured from all available family members using a thymidine synchronisation technique. The father and sib II.4 were 46,XY. The mother's karyotype was interpreted as $46, \mathrm{XX}$,ins $(7 ; 6)$ (q21.11;q22.1q23.3), which represents a balanced direct insertion of chromosome 6q22.1 $\rightarrow 6 \mathrm{q} 23.3$ into band q21.11 on chromosome 7 (fig 2). Cases 1 and 2 were found to carry the mother's altered chromosome 7 , namely der(7)ins(7;6)(q21.11;q22.1q23.3)mat, in addition to two normal copies of chromosome 6 , which represents trisomy for the region $6 \mathrm{q} 22.1 \rightarrow 6 \mathrm{q} 23.3$. FISH, conducted according to the manufacturer's instructions and performed with a chromosome 6 paint and chromosome $6 \mathrm{q}$ telomeric sequences, confirmed the presence of trisomy 6 and the interstitial nature of the insertion (fig 3).

The external clinical features and karyotype of the 11 previously published cases of "pure" partial trisomy 6q, together with the present cases, are summarised in table 1 .
The eight cases on the left hand side (group I) have in common an overlap of the region $6 \mathrm{q} 26 \rightarrow 6 \mathrm{q} 27$. The five cases on the right hand side of the table (group II) represent varied areas of partial trisomy $6 \mathrm{q}$ (fig 4 ). The cases comprise nine males and four females. In both our family and those previously described, ${ }^{21}{ }^{22}$ the inherited insertion was maternal in origin. Of the inherited translocations with deletion of ribosomal material, two were paternal ${ }^{17}{ }^{18}$ and three were maternal in origin. ${ }^{219}{ }^{20}$ In two cases ${ }^{23}{ }^{25}$ the observed duplication was de novo and in one case $^{24}$ the origin was not able to be determined.

All cases, sufficiently old to assess, exhibited some form of mental retardation and in all cases the majority of the dysmorphism was craniofacial. Despite the relatively large areas of duplicated genetic material, major organ malformation does not appear to be frequently involved in the partial trisomy $6 \mathrm{q}$ syndrome. Only two cases $^{17}{ }^{20}$ died in infancy, both from complications arising from cardiac anomalies; the oldest reported case ${ }^{21}$ was 19 years old. Group I cases, with the overlap of $6 \mathrm{q} 26 \rightarrow 6 \mathrm{q} 27$, are characterised by growth retardation, microcephaly, micrognathia, and a short webbed neck. These features are not often found in the group II cases, which adds weight to $6 \mathrm{q} 26 \rightarrow 6 \mathrm{q} 27$ being the critical region for this phenotype. This was first suggested by Turleau and de Grouchy ${ }^{2}$ and was further defined by Brøndum-Nielsen et $a l^{25}$ whose patient lacked duplication of the 6q27 telomeric sequences. Midfacial hypoplasia is observed only in our patients and that of Henegariu et $a l,{ }^{24}$ which may or may not be related to the common breakpoint at $6 \mathrm{q} 23.3$. A sleep study was performed in case 1 to exclude OSA in view of his symptoms (noisy breathing, snoring, poor school performance) and the association between midfacial hypoplasia and obstructive sleep apnoea. ${ }^{26}$ Despite the severe midfacial hypoplasia, case 1 did not have OSA.

To our knowledge, trisomy for the region $6 \mathrm{q} 22.1 \rightarrow 6 \mathrm{q} 23.3$ has not been previously reported. We observed the phenotype to be quite different from that recorded in cases which have an overlap of the $6 \mathrm{q} 26 \rightarrow 6 \mathrm{q} 27$ region. Traits in common to subjects with different areas of trisomy are probably the result of perturbation of multifactorial gene interaction. The currently known genes for disorders (deafness, argininaemia, cardiomyopathy, and hereditary persistence of fetal haemoglobin), proteins (phospholamban, myristoylated alanine rich protein kinase C substrate, protein L-isoaspartate O-methyltransferase, glucocorticoid regulated kinase, immunodeficiency virus type I enhancer binding protein-2, immune interferon receptor, transcription factor 21 , and connective tissue growth factor), and DNA sequences (six-twelve leukaemia 
gene and non-coding transcript in $\mathrm{T}$ cells) within $6 \mathrm{q} 22.1 \rightarrow 6 \mathrm{q} 23.3$ do not appear to be related to the observed features. While the phenotype must represent the effect of the triplicated genes in this area, there remains much to be discovered about the mechanisms involved.

This investigation was supported by grant (RP 3690022/N) from the National Medical Research Council of Singapore.

DENISE L M GOH ${ }^{\star}$ ARNOLD S C TAN ${ }^{\star}$

JEAN Y C CHEN + JANETTE A VAN DEN BERGHE† ${ }^{\star}$ Department of Paediatrics, Faculty of Medicine, National University of Singapore, Lower Kent Ridge Road, Singapore 119074, Republic of Singapore

$\dagger$ National University Medical Institutes, Faculty of Medicine, National University of Singapore, Singapore

$\ddagger$ Present address: Department of Pediatrics, Ellis Hall, Royal University Hospital, Saskatoon, Saskatchewan S7N 0W8, Canada.

Correspondence to: Dr Goh, paegohlm@nus.edu.sg

1 de Grouchy J, Emerit I, Aicardi J. Trisomie partielle pour le bras long d'un C (?6) par translocation t(Gp+;Cqs+). Ann Genet 1969;12:133-7.

2 Turleau C, de Grouchy J. Trisomy 6qter. Clin Genet 1981;19:202-6. Garcia-Heras J. Prenatal diagnosis of a de novo trisomy $6 \mathrm{q} 22.2 \rightarrow 6 \mathrm{qter}$ and monosomy 1 pter $\rightarrow 1$ p36.3. Case report with a 2 -year follow-up and a brief review of other prenatal cases of partial trisomy 6q. Clin Genet 1997;51:115-17

4 Chase TR, Jalal SM, Martsolf JT, Wasdahl WA. Duplication 6q24 $\rightarrow$ 6qter in an infant from a balanced paternal translocation. Am f Med Genet 1983;14: 347-51

5 Schroer RJ, Culp DM, Stevenson RE, Potts WE, Taylor HA, Simensen RJ. Duplication-deletion syndrome in a family with pericentric inversion of chromosome 6. Clin Genet 1980;18:83-7.

6 Neu RL, Gallien JU, Steinberg-Warren N, Wynn RJ, Bannermen RM. An infant with trisomy 6q21 $\rightarrow$ 6qter. Ann Genet 1981;24:167-9.

7 Clark CE, Cowell HR, Telfer MA, Casey PA. Trisomy 6q25 $\rightarrow 6$ qter in two sisters resulting from maternal 6;11 translocation. Am f Med Genet 1980;5: 171-8.

8 Erdel M, Duba HC, Verdorfer I, Lingenhel A, Geiger R, Gutenberger KH, Ludescher E, Utermann B, Utermann G. Comparative genomic hybridiza- tion reveals a partial de novo trisomy 6q23-qter in an infant with congenital malformations: delineation of the phenotype. Hum Genet 1997;99:596601

9 Schmid W, D’Apuzzo V, Rossi E. Trisomy 6q25 $\rightarrow$ 6qter in a severely retarded 7-year-old boy with turricephaly, bow-shaped mouth, hypogenitalism and club feet. Hum Genet 1979;46:279-84.

10 Uhrich S, FitzSimmons J, Easterling TR, Mack L, Disteche CM. Duplication (6q) syndrome diagnosed in utero. Am 7 Med Genet 1991;41:282-3.

11 Dallapiccola B, Bricarelli FD, Quartino AR, Mazzilli MC, Chisci R, Gandini E. Delineation of syndromes due to partial $6 \mathrm{q}$ imbalances. Trisomy $6 \mathrm{q} 21 \rightarrow \mathrm{qter}$ and monosomy $6 \mathrm{q} 221 \rightarrow \mathrm{qter}$ in two unrelated patients. Acta Genet Med Gemellol 1978;27:57-66.

12 D'Emma C, Crippa L, Delozier C, Michail E, Graber P. Observation familiale de trisomie partielle du 6 et monosomie partielle 18q probable par translocation parentale. F Genet Hum 1982;30:39-50.

13 Sommer A, Westman J, Stallard R. Partial trisomy 6q. Proc Greenzood Genet Center 1984;3:22-5

14 Tipton RE, Berns JS, Johnson WE, Wilroy RS Jr, Summitt RL. Duplication 6q syndrome. Am f Med Genet 1979;3:325-30.

15 Fitch N. Partial trisomy 6. Clin Genet 1978;14:181-5.

16 Robertson KP, Thurmon TF, Tracy MC. Acrocephalosyndactyly and partial trisomy 6. Birth Defects 1975;XI(5):267-71.

17 Pivnick EK, Qumsiyeh MB, Tharapel AT, Summitt JB, Wilroy RS. Partial duplication of the long arm of chromosome 6: a clinically recognisable syndrome. F Med Genet 1990;27:523-6.

18 Conrad BA, Higgins RR, Pierpont MEM. Duplication 6q22 $\rightarrow$ qter: definition of the phenotype. Am F Med Genet 1998;78:123-6.

19 Taysi K, Chao WT, Monaghan N, Monaco MP. Trisomy 6q22 $\rightarrow$ qter due to maternal 6;21 translocation. Ann Genet 1983;26,4:243-6.

20 Stamberg J, Shapiro J, Valle D, Kuhajda FP, Thomas G, Wissow L. Partial trisomy $6 \mathrm{q}$, due to balanced maternal translocation $(6 ; 22)(\mathrm{q} 21 ; \mathrm{p} 13)$ or (q21;pter). Clin Genet 1981;19:122-5.

21 Chen H, Tyrkus M, Cohen F, Woolley PV Jr, Mayeda K, Borgaonker A, Espiritu CE, Simpson W. Familial partial trisomy 6q syndromes resulting from inherited ins $(5 ; 6)(\mathrm{q} 33 ; \mathrm{q} 15 \mathrm{q} 27)$. Clin Genet 1976;9:631-7.

22 Pierpont MEM, MacCarthy KG, Knobloch WH. Partial trisomy 6q and bilateral retinal detachment. Ophthal Paediatr Genet 1986;7:175-80.

23 Giordino D, Rizzi N, Briscioli V, Bettio D. A de novo 6q11-q15 duplication investigated by chromosome painting. Clin Genet 1994;46:377-9.

24 Henegariu O, Heerema NA, Vance GH. Mild "duplication 6q syndrome": a case with partial trisomy (6)(q23.3q25.5). Am f Med Genet 1997;68:450-4.

25 Brøndum-Nielsen K, Bajalica S, Wulff K, Mikkelsen M. Chromosome painting using FISH (fluorescence in situ hybridization) with chromosome6 -specific library demonstrates the origin of a de novo $6 \mathrm{q}+$ marker chromosome. Clin Genet 1993;43:235-9.

26 Hui S, Wing YK, Kew J, Chan YL, Abdullah V, Fok TF. Obstructive sleep apnea syndrome in a family with Crouzon's syndrome. Sleep 1998;21:298303.

\section{A de novo complex chromosomal rearrangement involving chromosomes} 2,3 , and 10 associated with microcephaly and early onset spasticity

EDITOR-Hereditary spastic paraplegia, spastic paraplegia, or familial spastic paraplegia (HSP, SPG, or FSP) are a heterogeneous group of syndromes characterised by degeneration of corticospinal tracts. Currently, two loci for the $\mathrm{X}$ linked recessive type are well established, at Xq28 (SPG1, MIM 312900) ${ }^{1}$ and at Xq22 (SPG2, MIM 312920). ${ }^{2}$ Six loci for the autosomal dominant type have been reported, at 14q12-q23 (SPG3, MIM 182600), ${ }^{4}$ at 2p21-p24 (SPG4, MIM 182601), ${ }^{5}$ at 15q11.1 (SPG6, MIM 600363), ${ }^{7}$ at 8q23-q24 (SPG8, MIM 603563), ${ }^{8}$ at 10q23.3-q24.1 (SPG9, MIM 601162), ${ }^{9}$ and at 12q13 (SPG10, MIM 604187). ${ }^{10}$ Two loci for the autosomal recessive type were mapped to 8p12-q13 (SPG5A, MIM $270800)^{11}$ and to $16 \mathrm{q} 24.3$ (SPG7, MIM 602783), ${ }^{12}$ respectively.

HSPs are clinically subdivided into pure and complicated forms. The autosomal dominant form can be complicated by dementia and epilepsy. ${ }^{14}$ The $\mathrm{X}$ linked form can be more severe if combined with ataxia, absent extensor pollicis longus, and involvement of cerebral cortex and optic nerves (SPG1). The complicated autosomal recessive type is rare and is described as microcephaly with f Med Genet 2000;37:892-896

spastic quadriplegia (MIM 251280). ${ }^{15-19}$ The fact that familial cases were reported, where no linkage to any of the previously mentioned loci could be found, suggests that additional gene loci for hereditary spastic paraplegia exist. ${ }^{20}{ }^{21}$ The genetic heterogeneity supports the concept of a multitude of different genes responsible for spastic paraplegia. Since, however, a marked clinical similarity is found within HSP families with positive linkage to each of the reported loci, it was proposed that gene products from HSP loci may participate in a common biochemical cascade which, if disturbed, results in axonal degeneration that is most pronounced at the ends of the longest CNS axons. ${ }^{22}$

Complex chromosomal rearrangements (CCRs) are defined as any structural rearrangement involving more than two chromosome breaks with exchange of segments between at least two chromosomes. ${ }^{23}$ Rearrangements with up to seven derivative chromosomes ${ }^{24}$ and 10 breakpoints $^{25}$ have been reported. Batanian et $a l^{26}$ reviewed 100 published CCR cases. The detection and interpretation of CCRs is most efficiently achieved by a combination of classical cytogenetic methods, including high resolution banding techniques and FISH using both whole chromosome painting and band specific probes. ${ }^{27}$ Recently, multicolour FISH assays have been developed which allow the identification of cryptic translocations, marker chromosomes, and delineation of complex chromosomal aberrations in a single experiment. Based on cross species colour banding technology, RxFISH combines traditional banding capability with colour classification and allows also the 
detection of intrachromosomal rearrangements, such as duplications, deletions, insertions, and inversions. ${ }^{28}$

The strategy for a detailed characterisation of the chromosomal breakpoints of the CCR involving chromosomes 2, 3, and 10 was based on $\mathrm{RxFISH}$ and detailed mapping of single site specific YAC clones selected from the CEPH "MegaYAC" library. We analysed the chromosomal breakpoints in order to narrow down the region for putative candidate genes involved in the phenotype of the patient.

The proband, a $2 \frac{1}{2}$ year old boy with severe psychomotor retardation, is the first child of non-consanguineous parents. At the time of birth, the mother was 28 and the father 31 years old. He was born at 41 weeks of gestation following an uneventful pregnancy. Birth weight was 2480 g and Apgar scores were 8/9/10. During the neonatal period general muscular hypotonia combined with hyperreflexia of the lower limbs and the presence of bilateral Babinski signs was noticed. In the first months of life, two episodes of complicated febrile convulsions (EEG normal) occurred. At 12 months, psychomotor development was classified as markedly delayed on a clinical examination. At this time, microcephaly with a head circumference of 44 $\mathrm{cm}(-2.4 \mathrm{SD})^{29}$ with normal cranial MRI was recorded. Additional clinical abnormalities, such as epicanthus, a broad nasal root, severe myopia, a strabismus convergens alternans, slightly dysplastic ears with a preauricular fistula on the right side, a sacralporus, and hypopigmented skin were noticed (fig 1). Cardiac ultrasound and ECG were normal. All standard laboratory parameters were within the normal range as were results of amino acid analysis and of very long chain fatty acid screening. At the age of 16 months, spasticity with lower limb predominance became evident and developed to quadriplegia with preserved but considerably reduced motor function of the left upper extremity. At 26 months, his weight is $12.2 \mathrm{~kg}(-0.42 \mathrm{SD})$ and head circumference $47 \mathrm{~cm}(-1.8 \mathrm{SD})$. The Babinski sign is present bilaterally. $\mathrm{He}$ can sit independently but is still unable to walk. He has good eye contact but his social interactions are poor. He does not show any speech development so far, but apparently understands simple commands. Despite extensive testing, no exogenous causes for the psychomotor retardation and the quadriplegia could be found.

Chromosomes of the proband and his parents were investigated using BrdU synchronised cultures in order to obtain preparations suitable for high resolution analysis. ${ }^{30}$ A lymphoblast cell line of the patient was established from whole blood according to standard procedures.

YAC clones and information on positive STS hits were taken from Whitehead YAC contigs. ${ }^{31}$ DNA from CEPH "MegaYAC" clones were isolated by pulsed field gel electrophoresis and amplified by using degenerate oligonucleotide primed (DOP)-PCR to generate probes for FISH analysis. ${ }^{32}$ RxFISH (Applied Imaging International Ltd),

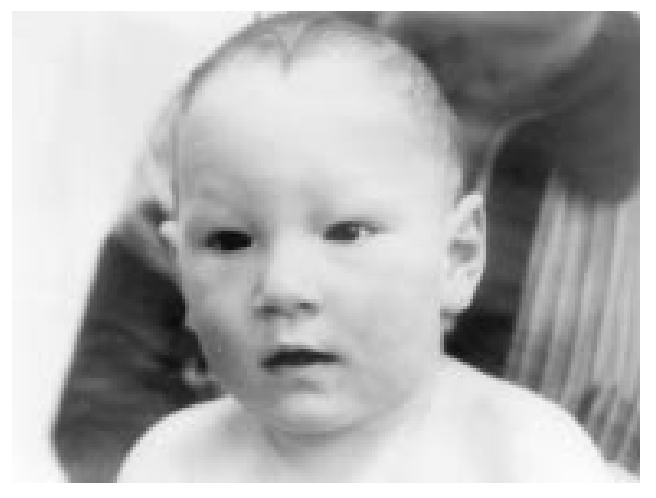

Figure 1 The proband aged 12 months. and FISH with a subtelomeric probe from 2q HBSP(Research Genetics) and the human pantelomeric probe (ID labs Inc) were performed on standard metaphase spreads according to the recommendations of the suppliers.

Images were recorded using a Zeiss axiophot microscope equipped with a cooled CCD camera (Photometrics). Digitised images were captured and processed on a CytoVision Ultra workstation (Applied Imaging International Ltd).

Conventional cytogenetic examinations on $\mathrm{G}$ banded metaphases of the proband showed a CCR of chromosomes 2, 3, and 10. Using high resolution chromosome banding, the translocation breakpoints were mapped to $2 \mathrm{q} 37.3,3 \mathrm{p} 22.3$, and $10 \mathrm{q} 25.2$. Therefore, the karyotype is $46, X Y, t(2 ; 3 ; 10)(2$ pter $\rightarrow 2 q 37.3:: 10 q 25.2 \rightarrow 10$ qter;3qter $\rightarrow$ 3p22.3::?2pter; 10pter $\rightarrow 10 \mathrm{q} 25.2:: 3$ p22. 3 $\rightarrow 3$ pter)de novo. A partial ideogram and high resolution karyotype is shown in fig 2. Analysis of the parental chromosomes did not show any abnormalities.

RxFISH (Applied Imaging International, UK), performed on metaphase spreads of the proband, was used to analyse the whole genome for further inter- and intrachromosomal rearrangements in a single assay. Cytogenetic findings were confirmed by this technique and no further rearrangements have been detected (data not shown).

For a detailed mapping of the chromosomal breakpoints, FISH studies were performed on metaphase preparations using numerous YAC clones from the chromosomal regions 3p22.1-p22.3 and 10q24.3-q25.3, which were selected by searching the genome database (GDB). Results of our FISH analysis are summarised in table 1.

Five of the chromosome 3 YAC clones (720_d_5, 793_g_8, 807_d_1, 938_g_7, 938_h_11) are assigned distal to the breakpoint. However, the more proximal YAC clones 750_d_3 and 802_g_1 show signals on the normal

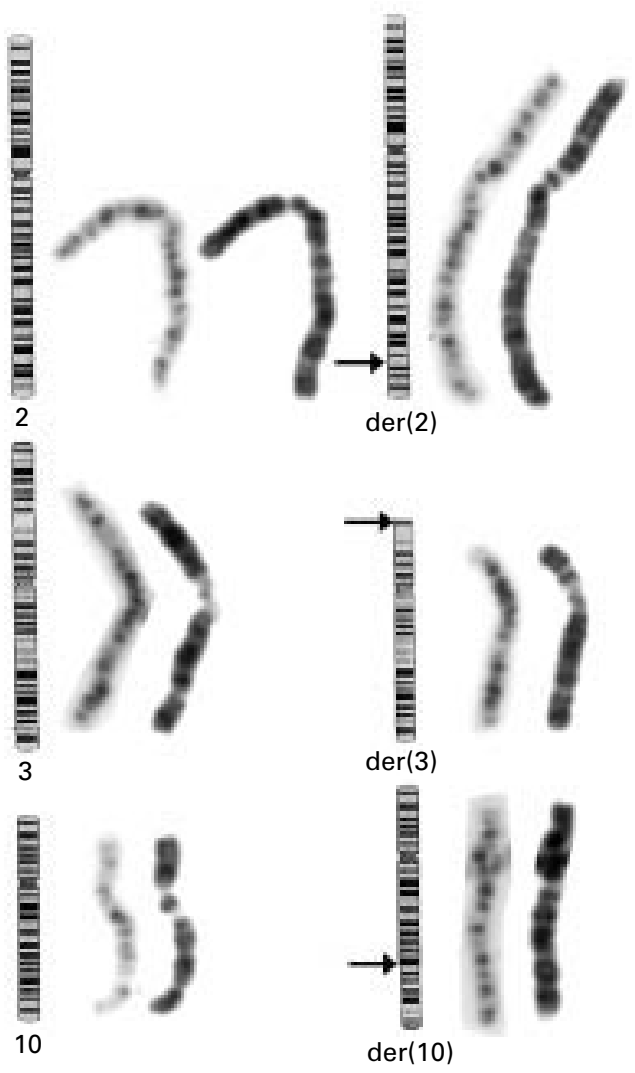

Figure 2 Partial ideogram and high resolution karyotype ( $G$ and $R$ bands) of the proband. The breakpoints are indicated by arrows. 
Table 1 Summary of FISH mapping experiments using YACs

\begin{tabular}{|c|c|c|c|}
\hline$Y A C$ clones & Cytogenetic location * & Size $(k b)^{\star}$ & Location on derivativest \\
\hline 720 d_5 & $3 \mathrm{p} 22.3$ & 750 & $\operatorname{der}(10)$ \\
\hline 793_g_8 & & 1490 & $\operatorname{der}(10)$ \\
\hline $807 \mathrm{~d}$ & & 1690 & $\operatorname{der}(10)$ \\
\hline 938_g_7 & & 1640 & $\operatorname{der}(10)$ \\
\hline 938_h_11 & & 1600 & $\operatorname{der}(10)$ \\
\hline $750 \_d \_3$ & & 1550 & $\operatorname{der}(2) / \operatorname{der}(10)$ \\
\hline 802_g_1 & & 1010 & $\operatorname{der}(2) / \operatorname{der}(10)$ \\
\hline 712_a_7 & $3 \mathrm{p} 22.1$ & 1330 & $\operatorname{der}(3)$ \\
\hline 758_g_3 & & 1340 & $\operatorname{der}(3)$ \\
\hline 810_c_8 & $10 \mathrm{q} 24.3$ & 1450 & $\operatorname{der}(10)$ \\
\hline 803 d_11 & & 1270 & $\operatorname{der}(10)$ \\
\hline 970_d_9 & $10 \mathrm{q} 25.1$ & 1230 & $\operatorname{der}(10)$ \\
\hline $962 \mathrm{~h} \_2$ & & 1130 & $\operatorname{der}(10)$ \\
\hline 806_h_8 & & 1590 & $\operatorname{der}(2) / \operatorname{der}(10)$ \\
\hline 792_a_10 & $10 \mathrm{q} 25.2$ & 580 & $\operatorname{der}(2)$ \\
\hline
\end{tabular}

^Data taken from the genome database.

Indicates the location of signals in addition to the normal chromosomes 3 or 10 , respectively.

chromosome 3, the $\operatorname{der}(10)$, and the $\operatorname{der}(2)$ indicating a cryptic insertion of chromosome 3 material into the telomeric region of the long arm of chromosome 2 (fig 3, above). Unfortunately, the second breakpoint on chromosome 3 is, according to chromosomal 3 linkage data from GDB, about $3 \mathrm{cM}$ proximal to the other breakpoint mentioned above and apparently maps to a gap between the Whitehead contigs 3.6 and 3.7. The YAC clones 712_a_7 and 758_g_3 gave hybridisation signals proximal to both chromosome 3 breakpoints.

To refine the localisation of the translocation breakpoint on the long arm of chromosome 10, six YAC clones specific for 10q24.3-10q25.3 were used for FISH experiments. Among those clones YAC 806_h_8 was found to span the chromosomal breakpoint since it exhibits signals on chromosome 10, the der(10), as well as the $\operatorname{der}(2)$ (fig 3, below). Although additional signals on chromosomes 5 and 11 indicate that this YAC is chimeric, this does not affect the usefulness of this clone. The signal of a subtelomeric probe from $2 \mathrm{q}$ (HBSP) is proximal to the inserted chromosome 3 material. However, by using a pantelomeric probe, no interstitial signal on the long arm of the derivative chromosome 2 could be obtained. As expected, a terminal signal of the pantelomeric probe is present on the short arm of the derivative chromosome 3 (data not shown). The karyotype according to ISCN (1995) nomenclature is $46, \mathrm{XY}, \mathrm{t}(2 ; 3 ; 10)(2 \mathrm{pter} \rightarrow 2 \mathrm{q} 37.3:: 10 \mathrm{q} 25.2 \rightarrow$ 10qter;3qter $\rightarrow 3$ p22.3::?2pter; 10pter $\rightarrow 10$ q25.2::3p22.3 $\rightarrow$ 3 ter).ish $\mathrm{t}(2 ; 3 ; 10)(2 \mathrm{pter} \rightarrow 2 \mathrm{q} 37.3:: 3 \mathrm{p} 22.3:: 10 \mathrm{q} 25.2 \rightarrow 10$ qter; 3qter $\rightarrow 3$ p22.3::?2pter; 10pter $\rightarrow 10$ q25.2::3p2 $2.3 \rightarrow 3$ pter)(2qter+, 750_d_3+, 802_g_1+,806_h_8+;712_a_7+, pantel+;806_h_8+,750_d_3+,80 2_g_1+,938_h_11+).

In our investigation we used a de novo complex chromosomal translocation which evolved as a consequence of two chromosomal breakage events on chromosome 3 and one on each of chromosomes 10 and 2. The most striking clinical features of the proband, besides the spastic quadriplegia, are microcephaly, psychomotor retardation, and distinct facial dysmorphic signs. Spasticity without detectable brain malformation is a very uncommon finding in patients with chromosomal aberrations. Even if we consider the fact that temporary spasticity is a common finding in microcephalic patients with psychomotor retardation, the clinical similarity, especially to microcephaly with spastic quadriplegia (MIM 251280), strongly suggests that at least one critical gene is affected by one of the breakpoints of this CCR. An extensive database search for genes already mapped to the chromosomal subbands $2 \mathrm{q} 37.3$ and 3 p22.3 has shown no potential candidate gene so far, which is likely to be associated with spasticity and related motor neurone syndromes. On the other hand, the breakpoint on chromosome 10 is located near the recently published region for SPG9 (10q23.3-q24.2) and within a chromosomal region (10q23.3-q25.2) which is associated with different neurological disorders, including partial epilepsy at 10q24 (MIM 600512), ${ }^{33}$ infantile onset spinocerebellar ataxia with sensory neuropathy between D10S192 and D10S1265 (MIM 271245), ${ }^{34}$ and progressive external ophthalmoplegia between D10S198 and D10S562 (MIM 157640)..$^{35}$

CCRs diagnosed by standard cytogenetic analysis are frequently combined with further cryptic rearrangements, ${ }^{36}$ which can only be resolved by a detailed molecular cytogenetic analysis using more sophisticated FISH methods. New techniques such as RxFISH are capable, at a higher level of resolution, of verifying or ruling out major additional rearrangements down to several megabases in a single FISH assay. However, it has to be emphasised that even rearrangements or structural abnormalities occurring between different chromosomes but within bands labelled with the identical colour will not be detected by RxFISH. In practice, only detailed mapping with single site specific YAC clones was sufficiently sensitive to show that a tiny fragment of chromosome 3 was translocated to chromosome 2 as well. The interstitial representation of the subtelomeric 2 qter probe on the derivative chromosome 2 and the fact that the pantelomeric probe showed no signal in this position but one terminal signal on the short arm of derivative chromosome 3 leads to the conclusion that either the breakpoint at $2 \mathrm{q} 37.3$ is precisely located between the subtelomeric and telomeric regions or telomeric repeats have been added by other mechanisms. ${ }^{37}$ By using YACs, which were previously assigned to contigs on chromosomes 3 and 10, we were also able to identify clones which cover two and flank one additional region of the chromosomal breakpoints of this CCR. Since one of the four breakpoints is located at the very end of the long arm of chromosome 2, distal even to the subtelomeric FISH probe we used, it is likely that this genomic region is of no relevance to the phenotype of the proband.

All the clinical findings could be the result of a loss or gain of function mutation of a single gene rearranged by one of the translocation events. Alternatively, an as yet unidentified submicroscopic deletion or duplication with partial aneusomy of a single or even several rearranged genes could be responsible for the phenotype. A loss or gain of chromosomal material was not detectable in our FISH analysis although an extremely small submicroscopic deletion, insertion, or duplication cannot be ruled out completely. In previous studies, it was convincingly shown that apparently balanced translocations can provide a very valuable resource for positional cloning of genes of interest. ${ }^{38}$ The breakpoint on chromosome 10 is within a chromosomal region associated with several neurological disorders. Well established methods for gene identification or isolation of transcribed sequences, such as direct cDNA selection or exon trapping, could be applied to the isolated YAC DNA as a next step to characterise the altered genomic region, which is most likely responsible for the clinical anomalies found in the proband.

In summary, FISH analysis with band specific probes derived from contigs from chromosomes 3 and 10 showed an unusual cryptic insertion and allowed very detailed characterisation of three out of four breakpoints in this CCR between chromosomes 2, 3, and 10. This CCR strongly suggests that a region of chromosome 10q defined by a single YAC (806_h_8) is likely to contain a gene for early onset paraplegia.

The molecular characterisation and biochemical studies will contribute to a better understanding of the pathogenic mechanism of this important neurological disorder. 

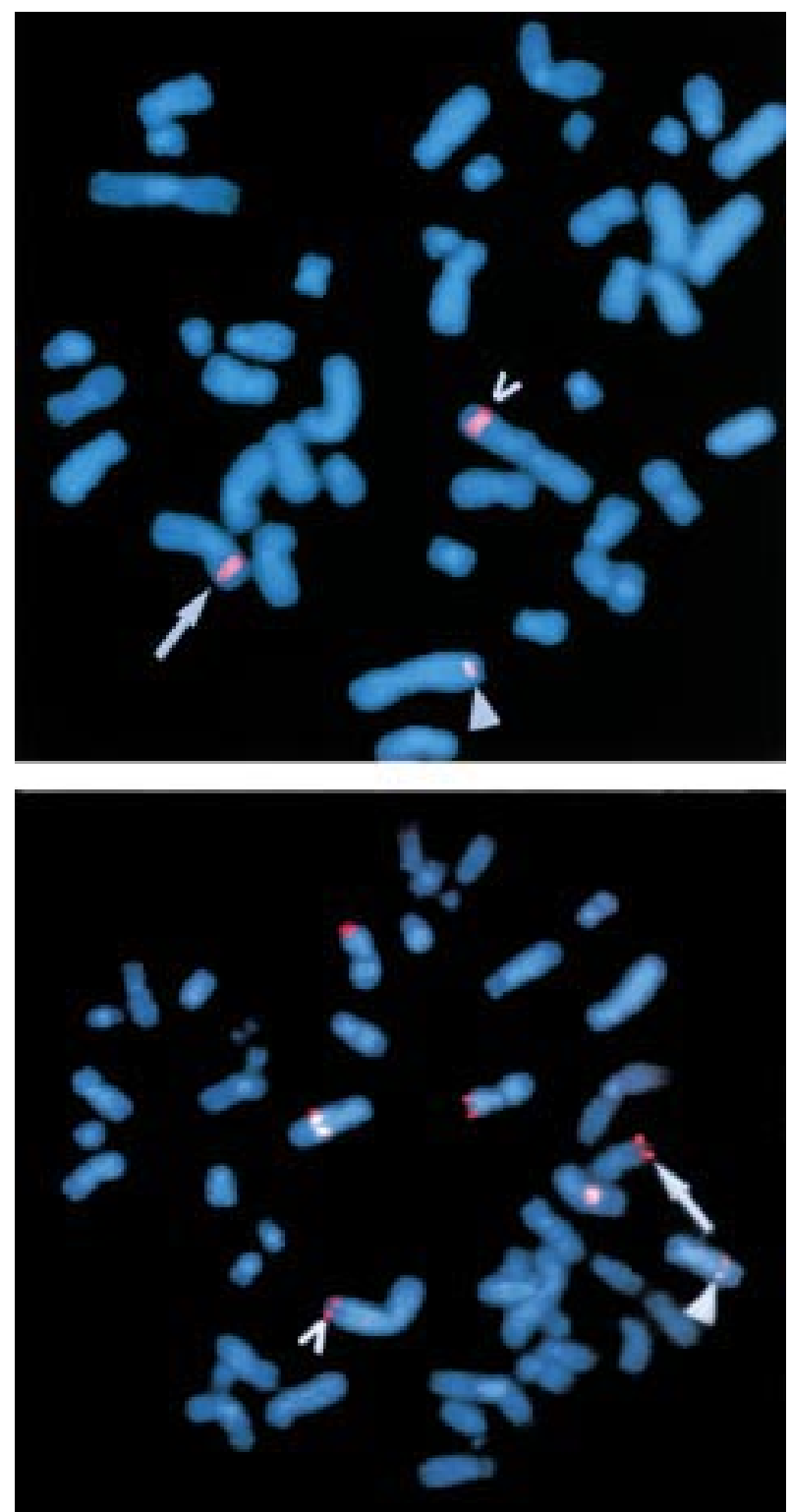

Figure 3 (Above) FISH mapping of YAC 750_d_3 to metaphase chromosomes of the patient shows hybridisation signals on the normal chromosome 3 (arrow), the der (2) (arrowhead), and the der (10) (open arrowhead), indicating that this YAC spans the distal translocation breakpoint on chromosome 3. (Below) FISH results obtained with YAC $806 \_h \_8$ which is spanning the translocation breakpoint on chromosome 10. Specific signals are localised on the normal chromosome 10 (arrow), the $\operatorname{der}(2)$ (open arrowhead), and the der(10) (arrowhead). Since 806_h_8 is a chimeric YAC, additional signals on chromosomes 5 and 11 can be seen. Rhodamine antidigoxigenin antibody was used to detect hybridisation sites on DAPI stained chromosomes.

Database information: Online Mendelian Inheritance in Man, OMIM (TM). Center for Medical Genetics, Johns Hopkins University (Baltimore, MD) and National Center for Biotechnology Information, National Library of Medicine (Bethesda, MD), 1997, World Wide Web URL: http://www.ncbi.nlm.nih.gov/ omim/ Genome Database, http://www.gdb.org

WERNER EMBERGER* ERWIN PETEK^

BARBARA PLECKO-STARTINIG† PETER M KROISEL * HANNELORE ZIERLER* KLAUS WAGNER*

*Institute of Medical Biology and Human Genetics, University of Graz, Harrachgasse 21/8, A-8010 Graz, Austria tDepartment of Paediatrics, University Hospital Graz, Graz, Austria Correspondence to: Dr Emberger, werner.emberger@kfunigraz.ac.at

1 Jouet M, Rosenthal A, Armstrong G, MacFarlane J, Stevenson R, Paterson J, Metzenberg A, Ionasescu V, Temple K, Kenwrick S. X-linked spastic paraplegia (SPG1), MASA syndrome and X-linked hydrocephalus result from mutations in the L1 gene. Nat Genet 1994;7:402-7.
2 Kobayashi H, Hoffman, EP, Marks HG. The rumpshaker mutation in spastic paraplegia. Nat Genet 1994;7:351-2.

3 Saugier-Veber P, Munnich A, Bonneau D, Rozet JM, Le Merrer M, Gil R, Boespflug-Tanguy $\mathrm{O}$. X-linked spastic paraplegia and PelizaeusMerzbacher disease are allelic disorders at the proteolipid protein locus. Nat Genet 1994;6:257-62.

4 Hazan J, Lamy C, Melki J, Munnich A, de Recondo J, Weissenbach J. Autosomal dominant familial spastic paraplegia is genetically heterogeneous and one locus maps to chromosome 14q. Nat Genet 1993;5:163-7.

5 Hazan J, Fontaine B, Bruyn RP, Lamy C, van Deutekom JC, Rime CS, Dürr A, Melki J, Lyon-Caen O, Agid Y. Linkage of a new locus for autosomal dominant familial spastic paraplegia to chromosome 2p. Hum Mol Genet 1994;3:1569-73.

6 Hentati A, Pericak-Vance MA, Lennon F, Wasserman B, Hentati F, Juneja T, Angrist MH, Hung WY, Boustany RM, Bohlega S. Linkage of a locus for autosomal dominant familial spastic paraplegia to chromosome $2 \mathrm{p}$ markers. Hum Mol Genet 1994;3:1867-71.

7 Fink JK, Wu CT, Jones SM, Sharp GB, Lange BM, Lesicki A, Reinglass T, Varvil T, Otterud B, Leppert $M$. Autosomal dominant familial spastic paraplegia: tight linkage to chromosome $15 \mathrm{q}$. Am $f$ Hum Genet 1995;56:188-92.

8 Hedera P, Rainier S, Alvarado D, Zhao X, Williamson J, Otterud, B, Leppert M, Fink JK. Novel locus for autosomal dominant hereditary spastic paraplegia, on chromosome 8q. Am f Hum Genet 1999;64:563-9.

9 Seri M, Cusano R, Forabosco P, Cinti R, Caroli F, Picco P, Bini R, Morra VB, De Michele G, Lerone M, Silengo M, Pela I, Borrone C, Romeo G, Devoto $M$. Genetic mapping to $10 \mathrm{q} 23.3-\mathrm{q} 24.2$, in a large Italian pedigree, Devoto $M$. Genetic mapping to $10 \mathrm{q} 23.3-\mathrm{q} 24.2$, in a large Italian pedigree,
of a new syndrome showing bilateral cataracts, gastroesophageal reflux, and of a new syndrome showing bilateral cataracts, gastroesophageal reflux, a

10 Reid E, Dearlove AM, Rhodes M, Rubinsztein DC. A new locus for autosomal dominant 'pure' hereditary spastic paraplegia mapping to chromosome 12q13, and evidence for further genetic heterogeneity. Am f Hum Genet 1999;65:757-63.

11 Hentati A, Pericak-Vance MA, Hung WY, Belal S, Laing N, Boustany RM, Hentati F, Ben Hamida M, Siddique T. Linkage of 'pure' autosomal recessive familial spastic paraplegia to chromosome 8 markers and evidence of genetic locus heterogeneity. Hum Mol Genet 1994;3:1263-7.

12 Casari G, De Fusco M, Ciarmatori S, Zeviani M, Mora M, Fernandez P, De Michele G, Filla A, Cocozza S, Marconi R, Durr A, Fontaine B, Ballabio A. Spastic paraplegia and OXPHOS impairment caused by mutations in paraplegin, a nuclear-encoded mitochondrial metalloprotease. Cell 1998; paraplegin,

13 De Michele G, De Fusco M, Cavalcanti F, Filla A, Marconi R, Volpe G, Monticelli A, Ballabio A, Casari G, Cocozza S. A new locus for autosomal recessive hereditary spastic paraplegia maps to chromosome 16q24.3. Am f Hum Genet 1998;63:135-9.

14 Gigli GL, Diomedi M, Bernardi G, Placidi F, Marciani MG, Calia E, Maschio MC, Neri G. Spastic paraplegia, epilepsy, and mental retardation in several members of a family, a novel genetic disorder. Am f Med Genet 1993;45:711-16.

15 Bundey SE, Hill EE. Recessive microcephaly with spastic quadriplegia. Unpublished data, 1975.

16 Bundey S, Griffiths MI. Recurrence risks in families of children with symmetrical spasticity. Dev Med Child Neurol 1977;19:179-91.

17 Tolmie JL, McNay M, Stephenson JBP, Doyle D, Connor JM. Microcephaly: genetic counselling and antenatal diagnosis after the birth of an affected child. Am f Med Genet 1987;27:583-94

18 Silengo M, Lerone M, Martinelli M, Martucciello G, Caffarena PE, Jasonni V, Romeo G. Autosomal recessive microcephaly with early onset seizures and spasticity. Clin Genet 1992;42:152-5.

19 Gross-Tsur V, Joseph A, Blinder G, Amir N. Familial microcephaly with severe neurological deficits: a description of five affected siblings. Clin Genet 1995;47:33-7.

20 Fink JK. Advances in hereditary spastic paraplegia. Curr Opin Neurol 1997; 10:313-18.

21 Kobayashi H, Garcia CA, Alfonso G, Marks HG, Hoffman EP. Molecular genetics of familial spastic paraplegia: a multitude of responsible genes. $\mathcal{F}$ Neurol Sci 1996;137:131-8.

22 Fink JK, Heiman-Patterson T, Bird T, Cambi F, Dubé MP, Figlewicz DA, Fink JK, Haines JL, Heiman-Patterson T, Hentati A, Pericak-Vance MA, Raskind W, Rouleau GA, Siddique T. Hereditary spastic paraplegia: advances in genetic research. Hereditary Spastic Paraplegia Working Group. Neurology 1996;46:1507-14

23 Pai GS, Thomas GH, Mahoney W, Migeon BR. Complex chromosome rearrangements. Clin Genet 1980;18:436-44.

24 Kousseff BG, Nichols P, Essig YP, Miller K, Weiss A, Tedesco TA. Complex chromosome rearrangements and congenital anomalies. Am f Med Genet 1987;26:771-82.

25 Tupler R, Maraschino P, Gerado A, Mainieri R, Lanzi G, Tiepolo L. A complex chromosome rearrangements with 10 breakpoints: tentative assignment of the locus for Williams syndrome to 4q33-q35.1. I Med Genet 1992;29:253-5.

26 Batanian JR, Eswara MS. De novo apparently balanced complex chromosome rearrangement (CCR) involving chromosomes 4,18 , and 21 in a girl with mental retardation: report and review. Am f Med Genet 1998;78:44-51.

27 Klever M, Grond-Ginsbach C, Scherthan H, Schroeder-Kurth TM. Chromosomal in situ suppression hybridization after Giemsa banding. Hum Genet 1991;86:484-6

28 Mueller S, Rocchi M, Ferguson-Smith MA, Wienberg J. Toward a multicolor chromosome bar code for the entire human karyotype by fluorescence in situ hybridisation. Hum Genet 1997;100:271-8.

29 Prader A, Largo RH, Molinari L, Issler C. Physical growth of Swiss children from birth to 20 years of age. Zurich longitudinal study of growth and development. Helv Paediatr Acta Suppl 1989;52:1-125.

30 Kroisel PM, Rosenkranz W. High resolution banding of an unusual reciprocal translocation in recurrent abortions. Clin Genet 1990;37:230-4.

31 Hudson TJ, Stein LD, Gerety SS, Ma J, Castle AB, Silva J, Slonim DK, Baptista R, Kruglyak L, Xu SH. An STS-based map of the human genome. Science 1995;270:1945-54.

32 Petek E, Kroisel PM, Wagner K. Isolation of site-specific insert probes from chimeric YACs. BioTechniques 1997;23:72-7.

33 Ottman R, Risch N, Hauser WA, Pedley TA, Lee JH, Barker-Cummings C, Lustenberger A, Nagle KJ, Lee KS, Scheuer ML, Neystat M, Susser M, 
Wilhelmsen KC: Localization of a gene for partial epilepsy to chromosome 10q. Nat Genet 1995;10:56-60

34 Nikali K, Isosomppi J, Lonnqvist T, Mao J, Suomalainen A, Peltonen L. Toward cloning of a novel ataxia gene: refined assignment and physical map of the IOSCA locus (SCA8) on 10924. Genon

35 Suomalainen A, Kaukonen J, Amati, P, Timonen R, Haltia M, Weissenbach

J, Zeviani M, Somer H, Peltonen L. An autosomal locus predisposing to deletions of mitochondrial DNA. Nat Genet 1995;9:146-51

36 Batista DAS, Tuck-Muller CM, Martinez JE, Kearns WG, Pearson PL, Stetten G. A complex chromosomal rearrangement detected prenatally and studied by fluorescence in situ hybridization. Hum Genet 1993;92:117-21. 7 Wilkie AOM, Lamb J, Harris PC, Finney RD, Higgs DR A truncated Wilkie AOM, Lamb J, Harris PC, Finney RD, Higgs DR. A truncated
human chromosome 16 associated with $\alpha$ thalassaemia is stabilized by human chromosome 16 associated with $\alpha$ thalassaemia is stabilized

38 Wirth J, Nothwang HG, van der Maarel S, Menzel C, Borck G, Lopez-Pajares I, Brøndum-Nielsen K, Tommerup N, Bugge M, Ropers $\mathrm{HH}$, Haaf T. Systematic characterisation of disease associated balanced chromosome rearrangements by FISH: cytogenetically and genetically anchored YACs identify microdeletions and candidate regions for mental retardation genes. F Med Genet 1999;36:271-8.

\section{CORRECTION}

In the September issue of the journal, on page 706 of the

Letter to the Editor by Beesley et al, on "Mutational analysis of Sanfilippo syndrome type A (MPS IIIA): identification of 13 novel mutations", the underlining in table 3 has unfortunately been printed too low. The corrected table is shown below.

Table 3 Mutations found in the sulphamidase gene from patients with MPS IIIA in this study

\begin{tabular}{|c|c|c|c|c|c|c|}
\hline Exon (fragment) & Mutation * & Nucleotide alteration * & Protein alteration & SSCP shift & $R E$ test & ACRS test (table 2) \\
\hline $2(2)$ & D32Gt & $\mathrm{GAC} \rightarrow \mathrm{GGC} 107 \mathrm{~A}>\mathrm{G}$ & Asp $\rightarrow$ Gly & - & & $-H i n c I I$ \\
\hline $2(2)$ & S66W & $\mathrm{T} \overline{\mathrm{C}} \mathrm{G} \rightarrow \mathrm{T} \overline{\mathrm{G}} \mathrm{G} 209 \mathrm{C}>\mathrm{G}$ & Ser $\rightarrow$ Trp & - & $+B s t \mathrm{NI}$ & \\
\hline $2(2)$ & $\mathrm{R} 74 \mathrm{C}$ & $\mathrm{C} \overline{\mathrm{G}} \mathrm{C} \rightarrow \mathrm{T} \overline{\mathrm{G}} \mathrm{C} 232 \mathrm{C}>\mathrm{T}$ & $\mathrm{Arg} \rightarrow \mathrm{Cys}$ & $+4^{\circ} \mathrm{C}$ & $-B s t \mathrm{UI}$ & \\
\hline $2(2)$ & T79P & $\overline{\mathrm{A}} \mathrm{CT} \rightarrow \overline{\mathrm{C}} \mathrm{CT} 247 \mathrm{~A}>\mathrm{C}$ & $\mathrm{Thr} \rightarrow$ Pro & $+4^{\circ} \mathrm{C}$ & $+B s t \mathrm{NI}$ & \\
\hline $3(3)$ & $\mathrm{H} 84 \mathrm{Y} \dagger$ & $\overline{\mathrm{C}} \mathrm{AT} \rightarrow \overline{\mathrm{T}} \mathrm{AT} 262 \mathrm{C}>\mathrm{T}$ & His $\rightarrow$ Tyr & $+4^{\circ} \mathrm{C}$ & $-F n u 4 \mathrm{HI}$ & \\
\hline $4(4)$ & G122R & $\overline{\mathrm{G}} \mathrm{GG} \rightarrow \mathrm{A} G \mathrm{G} 376 \mathrm{G}>\mathrm{A}$ & $\mathrm{Gly} \rightarrow \mathrm{Arg}$ & $+4^{\circ} \mathrm{C}$ & & $+D d e I$ \\
\hline $4(4)$ & R150W† & $\overline{\mathrm{C}} \mathrm{GG} \rightarrow \overline{\mathrm{T}} \mathrm{GG} 460 \mathrm{C}>\mathrm{T}$ & $\mathrm{Arg} \rightarrow \operatorname{Trp}$ & $+4^{\circ} \mathrm{C}$ & $-A c i \mathrm{I}$ & \\
\hline $6(6)$ & R233Xt & $\overline{\mathrm{C}} \mathrm{GA} \rightarrow \mathrm{T} G A 709 \mathrm{C}>\mathrm{T}$ & Arg $\rightarrow$ Stop & $+4^{\circ} \mathrm{C}$ & $-A v a \mathrm{I}$ & \\
\hline $6(6)$ & $\mathrm{D} 235 \mathrm{~N} \dagger$ & $\overline{\mathrm{G}} \mathrm{AC} \rightarrow \overline{\mathrm{A}} \mathrm{AC} 715 \mathrm{G}>\mathrm{A}$ & Asp $\rightarrow$ Asn & $+\mathrm{RT}$ & & $-T a q \mathrm{I}$ \\
\hline $6(6)$ & $\mathrm{R} 245 \mathrm{H}$ & $\overline{\mathrm{C}} \mathrm{GC} \rightarrow \overline{\mathrm{C}} \mathrm{AC} 746 \mathrm{G}>\mathrm{A}$ & Arg $\rightarrow$ His & $+4^{\circ} \mathrm{C}$ & $-E a g \mathrm{I}$ & \\
\hline $7(7)$ & $\mathrm{D} 273 \mathrm{~N}+$ & $\mathrm{GAC} \rightarrow \mathrm{A} \overline{\mathrm{AC}} 829 \mathrm{G}>\mathrm{A}$ & $\mathrm{Asp} \rightarrow \mathrm{Asn}$ & $+4^{\circ} \mathrm{C}$ & & $-B s i \mathrm{EI}$ \\
\hline $7(7)$ & S298P & $\overline{\mathrm{T}} \mathrm{CC} \rightarrow \overline{\mathrm{C}} \mathrm{CC} 904 \mathrm{~T}>\mathrm{C}$ & Ser $\rightarrow$ Pro & $+4^{\circ} \mathrm{C}$ & + MaeIII & \\
\hline $8(8 a)$ & I322St & $\mathrm{ATC} \rightarrow \mathrm{AGC} 977 \mathrm{~T}>\mathrm{G}$ & $\mathrm{Ile} \rightarrow \mathrm{Ser}$ & $+4^{\circ} \mathrm{C}$ & $+A l u \mathrm{I}$ & \\
\hline $8(8 a)$ & 1039insC & $1 \bar{b} p$ ins & 158 altered aa, term & $+4^{\circ} \mathrm{C}$ & $-B s t \mathrm{XI}$ & \\
\hline $8(8 a)$ & E355K† & $\mathrm{GAG} \rightarrow \mathrm{AAG} 1075 \mathrm{G}>\mathrm{A}$ & Glu $\rightarrow$ Lys & $+4^{\circ} \mathrm{C}$ & $-B s p 1286 \mathrm{I}$ & \\
\hline $8(8 a)$ & $1091 \mathrm{delC}$ & $\overline{1} \mathrm{bp}$ del & 51 altered aa, term & $+4^{\circ} \mathrm{C}$ & $+B s t \mathrm{XI}$ & \\
\hline $8(8 a)$ & E369X† & $\mathrm{GAG} \rightarrow$ TAG $1117 \mathrm{G}>\mathrm{T}$ & Glu $\rightarrow$ Stop & $+4^{\circ} \mathrm{C}$ & $+B f a \mathrm{I}$ & \\
\hline $8(8 a)$ & $\mathrm{Y} 374 \mathrm{H} \dagger$ & $\overline{\mathrm{T}} \mathrm{AC} \rightarrow \overline{\mathrm{CAC}} 1132 \mathrm{~T}>\mathrm{C}$ & $\mathrm{Tyr} \rightarrow \mathrm{His}$ & - & & $+\operatorname{Sau} 96 \mathrm{I}$ \\
\hline $8(8 a)$ & 1156-1157ins6† & $\overline{6} \mathrm{bp}$ ins $\mathrm{AGCGCC}$ & ins Gln Arg & $+4^{\circ} \mathrm{C}$ & $+\mathrm{Hae} \mathrm{II}$ & \\
\hline $8(8 b)$ & 1284del11 & $11 \mathrm{bp}$ del & 1 altered aa, term & $+4^{\circ} \mathrm{C}$ & $-R s a \mathrm{I}$ & \\
\hline $8(8 b)$ & 1307 del 9 & 9 bp del & del 3 aa & $+4^{\circ} \mathrm{C}$ & $-B s t \mathrm{UI}$ & \\
\hline $8(8 b)$ & $\mathrm{R} 433 \mathrm{~W}+$ & $\mathrm{CGG} \rightarrow \mathrm{TGG} 1309 \mathrm{C}>\mathrm{T}$ & Arg $\rightarrow$ Trp & $+\mathrm{RT}$ & $+B s r \mathrm{I}$ & \\
\hline $8(8 b)$ & V486Ft & $\overline{\mathrm{GTC}} \rightarrow \mathrm{TTC} 1468 \mathrm{G}>\mathrm{T}$ & $\mathrm{Val} \rightarrow \mathrm{Phe}$ & - & $-B s a \mathrm{HI}$ & \\
\hline
\end{tabular}

${ }^{\star}$ Number of codons and nucleotides according to ref 6 .

†Novel mutations. 